\title{
Selective Effects of PDE10A Inhibitors on Striatopallidal Neurons Require Phosphatase Inhibition by DARPP-32 $2^{1,2,3}$
}

\author{
Marina Polito, ${ }^{1,2}$ Elvire Guiot, ${ }^{1,2}$ Giuseppe Gangarossa, ${ }^{3,4,5}$ Sophie Longueville, ${ }^{2,6,7}$ Mohamed \\ Doulazmi, ${ }^{1,2}$ Emmanuel Valjent, ${ }^{3,4}$ Denis Hervé, ${ }^{2,6,7}$ Jean-Antoine Girault, ${ }^{2,6,7}$ Danièle \\ Paupardin-Tritsch, ${ }^{1,2}$ (ㄴ) Liliana R. V. Castro, ${ }^{1,2}$ and ${ }^{-1}$ Pierre Vincent ${ }^{1,2}$
}

\section{DOI:http://dx.doi.org/10.1523/ENEURO.0060-15.2015}

${ }^{1}$ CNRS, UMR8256 "Biological Adaptation and Ageing", Institut de Biologie Paris-Seine (IBPS), F-75005 Paris, France, ${ }^{2}$ Université Pierre et Marie Curie (UPMC, Paris 6), Sorbonne Universités, Paris, F-75005, France, ${ }^{3}$ CNRS, UMR-5203, Institut de Génomique Fonctionnelle, Montpellier, F-34094, France, ${ }^{4}$ Institut National de la Santé et de la Recherche Médicale, U661, Montpellier, F-34094, France, ${ }^{5}$ Universités de Montpellier 1 \& 2, UMR-5203, Montpellier, F-34094, France, ${ }^{6}$ Institut National de la Santé et de la Recherche Médicale UMR-S 839, Paris, France, and ${ }^{7}$ Institut du Fer à Moulin, Paris, France

\begin{abstract}
Type 10A phosphodiesterase (PDE10A) is highly expressed in the striatum, in striatonigral and striatopallidal mediumsized spiny neurons (MSNs), which express $D_{1}$ and $D_{2}$ dopamine receptors, respectively. PDE10A inhibitors have pharmacological and behavioral effects suggesting an antipsychotic profile, but the cellular bases of these effects are unclear. We analyzed the effects of PDE10A inhibition in vivo by immunohistochemistry, and imaged cAMP, cAMPdependent protein kinase A (PKA), and cGMP signals with biosensors in mouse brain slices. PDE10A inhibition in mouse striatal slices produced a steady-state increase in intracellular cAMP concentration in $D_{1}$ and $D_{2} M S N s$, demonstrating that PDE10A regulates basal CAMP levels. Surprisingly, the PKA-dependent AKAR3 phosphorylation signal was strong in $D_{2}$ MSNs, whereas $D_{1}$ MSNs remained unresponsive. This effect was also observed in adult mice in vivo since PDE10A inhibition increased phospho-histone $\mathrm{H3}$ immunoreactivity selectively in $\mathrm{D}_{2}$ MSNs in the dorsomedial striatum. The PKA-dependent effects in $\mathrm{D}_{2}$ MSNs were prevented in brain slices and in vivo by mutation of the PKA-regulated phosphorylation site of $32 \mathrm{kDa}$ dopamine- and cAMP-regulated phosphoprotein (DARPP-32), which is required for protein phosphatase-1 inhibition. These data highlight differences in the integration of the cAMP signal in $D_{1}$ and $D_{2} M S N s$, resulting from stronger inhibition of protein phosphatase-1 by DARPP-32 in $D_{2} M S N s$ than in $\mathrm{D}_{1}$ MSNs. This study shows that PDE10A inhibitors share with antipsychotic medications the property of activating preferentially PKA-dependent signaling in $\mathrm{D}_{2}$ MSNs.
\end{abstract}

Key words: biosensor imaging; cAMP; phosphodiesterase; protein kinase; schizophrenia; striatum

\section{Significance Statement}

The striatum is mainly composed of medium-sized spiny neurons that express either dopamine $D_{1}$ receptors or dopamine $D_{2}$ receptors. Their activity is associated with either the initiation of movement or action suppression, respectively. Biosensor imaging revealed that pharmacological inhibition of type 10A phosphodiesterase increased cAMP levels in $D_{1}$ and $D_{2}$ neurons in the same manner, but only $D_{2}$ neurons exhibited an increase in the protein kinase A-mediated phosphorylation level. This effect resulted from an asymmetrical regulation of phosphatases by DARPP-32. $D_{2}$ neurons are thus more prone to respond to a tonic cAMP signal than $D_{1}$ neurons, a property that may explain how phosphodiesterase $10 \mathrm{~A}$ inhibitors produced antipsychotic-like behavioral effects. This $D_{1} / D_{2}$ imbalance may also be critical for reward-mediated learning and action selection. 


\section{Introduction}

Schizophrenia is a devastating psychiatric disease, which results in persistent cognitive and emotional impairments. Type 10A phosphodiesterase (PDE10A) inhibitors were recently proposed as a treatment for schizophrenia (Kehler and Nielsen, 2011; Chappie et al., 2012); however, their cellular mechanisms of action remain unclear with respect to their putative therapeutic effects. PDE10A is highly and almost exclusively expressed in medium-sized spiny neurons (MSNs) of the striatum (Seeger et al., 2003; Coskran et al., 2006; Heiman et al., 2008; Lakics et al., 2010; Kelly et al., 2014). MSNs are divided into two categories based on their expression of dopamine receptors and their sites of projection, as follows: MSNs projecting to the substantia nigra highly express dopamine $D_{1}$ receptors (hereafter termed $D_{1}$ MSNs); whereas, MSNs projecting to the external globus pallidus highly express adenosine $A_{2 A}$ and dopamine $D_{2}$ receptors (hereafter termed $D_{2}$ MSNs; Gerfen et al., 1990; Le Moine and Bloch, 1995; Bertran-Gonzalez et al., 2008; Matamales et al., 2009). The high expression of PDE10A in MSNs, and its interaction with the scaffold protein AKAP150 (A-kinase anchoring protein 150), protein kinase A (PKA), PSD-95, and NMDA receptor suggests an important role in modulating the spread of the synaptic CAMP signals into the cell body (Russwurm et al., 2015).

Besides PDE10A, striatal neurons express a number of specific signaling proteins that markedly differ from those in other brain regions (Girault, 2012), and that determine the characteristics of the cAMP/PKA signaling pathway (Castro et al., 2013). Among these specific proteins, DARPP-32 (32-kDa dopamine and cAMP-regulated phosphoprotein) is a multifunctional protein regulating phosphatase and kinase activities: for example, when DARPP-32 is phosphorylated at threonine 34 residue (Thr34) by PKA, it becomes a potent inhibitor of serine/threonine protein phosphatase-1 (PP-1; Hemmings et al., 1984; Svenningsson et al., 2004), increasing the duration of PKA-dependent signals (Castro et al., 2013).

Received June 1, 2015; accepted August 10, 2015; First published August 25, 2015.

${ }^{1}$ The authors declare no competing financial interests.

${ }^{2}$ Author contributions: M.P., E.V., D.H., D.P.-T., L.R.V.C., and P.V. designed research. M.P., E.G., G.G., S.L., and L.R.V.C. performed research. M.P., E.G., G.G., S.L., M.D., L.R.V.C., and P.V. analyzed data. E.V., D.H., J.A.-G., D.P.-T., L.R.V.C., and P.V. wrote the paper.

${ }^{3}$ This work was supported by grants from ATIP-Avenir (Inserm) and from the Agence Nationale de la Recherche, ANR-2010-JCJC-1412) to EV and ANR09MNPS-014 to DH, and ERC to JAG. The groups of PV, and JAG and DH are part of the Bio-Psy Laboratory of Excellence.

Acknowledgments: Confocal microscopy and image analysis were performed at the Institut du Fer à Moulin Imaging Facilities and at the Institute of Biology Paris-Seine Imaging Facility (supported by the "Conseil Regional Ile-de France", the French National Research Council, and Sorbonne University, UPMC, Paris 6).

Correspondence should be addressed to Pierre Vincent, UMR8256, 9, quai St. Bernard, F-75005 PARIS, France. E-mail: pierre.vincent@upmc.fr.

DOI:http://dx.doi.org/10.1523/ENEURO.0060-15.2015

Copyright (C) 2015 Polito et al.

This is an open-access article distributed under the terms of the Creative Commons Attribution 4.0 International, which permits unrestricted use, distribution and reproduction in any medium provided that the original work is properly attributed.
Classical and atypical antipsychotic agents share the property of inhibiting $D_{2}$ receptors and thus, in the striatum, increase PKA-dependent phosphorylation selectively in $D_{2}$ MSNs (Bateup et al., 2008; Bertran-Gonzalez et al., 2008, 2009). In contrast, psychostimulants, which are psychotomimetic, activate many signaling responses in $\mathrm{D}_{1}$ MSNs (Bateup et al., 2008; Bertran-Gonzalez et al., 2008, 2009). PDE10A inhibitors were shown to increase cAMP levels in the striatum (Schmidt et al., 2008) and could be expected to mimic the effects of both antipsychotic and psychotomimetic compounds. We used biosensor imaging to precisely analyze the effects of PDE10A inhibitors on CAMP/PKA signaling at the level of individual $D_{1}$ and $D_{2}$ MSNs. Our work revealed that although PDE10A inhibition increased intracellular cAMP levels in both $D_{1}$ and $D_{2} M S N s$, the downstream consequences at the level of PKA targets were profoundly different: the CAMP signal resulting from PDE10A inhibition strongly increased PKA-dependent phosphorylation in $D_{2} M S N s$, whereas $D_{1}$ MSNs remained mostly unaffected. Further analyses showed that the difference required DARPP-32dependent regulation of phosphatase activity in $D_{1}$ and $D_{2}$ MSNs.

\section{Materials and Methods}

\section{Animals}

Animals were housed under standardized conditions with a $12 \mathrm{~h}$ light/dark cycle, stable temperature (22 \pm $\left.1{ }^{\circ} \mathrm{C}\right)$, controlled humidity ( $\left.55 \pm 10 \%\right)$, and food and water available ad libitum. Homozygous mice expressing DARPP-32 with the T34A or T75A mutation (Svenningsson et al., 2003) were obtained by crossing heterozygous mice, on a mixed C57BL6/J-Sv129 background (a gift of Dr. P. Greengard, The Rockefeller University, New York). Male Drd2-EGFP heterozygous mice (C57BI6/J) were generated as described previously (Gong et al., 2003). Experiments were performed in accordance with the regulations under the control of the local ethic committee Charles Darwin C2EA - 05.

\section{Live brain slice preparation}

Brain slices were prepared from male mice that were 8-12 days of age. Coronal brain slices were cut with a VT1200S microtome. Slices were prepared in an ice-cold solution of the following composition (in mM): $125 \mathrm{NaCl}, 0.4$ $\mathrm{CaCl}_{2}, 1 \mathrm{MgCl}_{2}, 1.25 \mathrm{NaH}_{2} \mathrm{PO}_{4}, 26 \mathrm{NaHCO}_{3}, 25$ glucose, and 1 kynurenic acid, saturated with $5 \% \mathrm{CO}_{2}$ and $95 \% \mathrm{O}_{2}$. The slices were incubated in this solution for $30 \mathrm{~min}$ and then placed on a Millicell-CM membrane (Millipore) in culture medium (50\% Minimum Essential Medium, 50\% HBSS, 6.5 $\mathrm{g} / \mathrm{L}$ glucose, penicillin-streptomycin; Invitrogen). We used the Sindbis virus as a vector to induce expression of the various biosensors after overnight incubation (Ehrengruber et al., 1999). The coding sequences of Epac-S ${ }^{H 150}$ (Polito et al., 2013), AKAR2-NLS (Zhang et al., 2005), AKAR3 (Allen and Zhang, 2006), and cygnet2 (Honda et al., 2001) were inserted into the viral vector pSinRep5 (Invitrogen). The viral vector $\left(\sim 5 \times 10^{5}\right.$ particles per slice) was added, and slices were incubated overnight at $35^{\circ} \mathrm{C}$ under an atmosphere containing $5 \% \mathrm{CO}_{2}$. Before the experiment, slices were 
incubated for $30 \mathrm{~min}$ in the recording solution $(125 \mathrm{~mm} \mathrm{NaCl}$, $2 \mathrm{mM} \mathrm{CaCl}_{2}, 1 \mathrm{~mm} \mathrm{MgCl}, 1.25 \mathrm{~mm} \mathrm{NaH}_{2} \mathrm{PO}_{4}, 26 \mathrm{~mm}$ $\mathrm{NaHCO}_{3}$, and $25 \mathrm{~mm}$ glucose, saturated with $5 \% \mathrm{CO}_{2}$ and $95 \% \mathrm{O}_{2}$ ). Recordings were performed with a continuous perfusion of the same solution at $32^{\circ} \mathrm{C}$. MSNs constitute $95 \%$ of neurons in the striatum. Large neurons (smallest soma diameter, $>14 \mu \mathrm{m}$ ), presumably cholinergic interneurons, were excluded.

\section{Live brain slice imaging}

For two-photon imaging, excitation was obtained using a Ti:sapphire laser (MaiTai HP; Spectra Physics) tuned at $850 \mathrm{~nm}$ for CFP excitation. Galvanometric scanners (model 6210; Cambridge Technology) were used for raster scanning, and a piezo-driven objective scanner (P-721 PIFOC; Physik Instrumente $\mathrm{GmbH}$ ) was used for $z$-stack image acquisition. The system was controlled by MPscope software (Nguyen et al., 2006). The microscope was based on an Olympus BX51WI upright microscope with a $40 \times 0.8$ numerical aperture (NA) or $60 \times 0.9 \mathrm{NA}$ water-immersion objective. A two-photon emission filter was used to reject residual excitation light (E700 SP; Chroma Technology). A fluorescence cube containing $479 / 40$ and $542 / 50$ emission filters and a $506 \mathrm{~nm}$ dichroic beamsplitter (FF01-479/40, FF01-542/50 and FF506Di02-25x36 Brightline Filters; Semrock) was used for the orthogonal separation of the two fluorescence signals. Two imaging channels (H9305 photomultipliers; Hamamatsu) were used for simultaneous detection of the two types of fluorescence emission. For each data point, an image stack of 30-40 images with a $0.5 \mu \mathrm{m}$ interval was acquired.

Wide-field images were obtained with an Olympus BX50WI or BX51WI upright microscope with a $40 \times 0.8 \mathrm{NA}$ water-immersion objective and an ORCA-AG Camera (Hamamatsu). Images were acquired with iVision (Biovision). The excitation and dichroic filters were D436/20 and 455dcxt. Signals were acquired by alternating the emission filters, HQ480/40 for CFP, and D535/40 for yellow fluorescent protein, with a filter wheel (Sutter Instruments). These filters were obtained from Chroma Technology.

No correction for bleed-through or direct excitation of the acceptor was applied, since this correction, while increasing the absolute amplitude of ratio changes, also increases the noise in the measurement (Ducros et al., 2009).

The biosensor chromophores are sensitive to nonspecific environmental disturbances. We used a mutated version of AKAR3 in which the threonine residue of the PKA phosphorylation site was replaced with an alanine residue (T391A) as a control. This AKAR3 (T391A) control sensor reported no ratio change in response to PDE10A inhibition in MSNs.

\section{Data analysis}

Images were analyzed with custom routines written in the IGOR Pro environment (Wavemetrics). The emission ratio was calculated for each pixel, as follows: F535/F480 for AKAR2-NLS and AKAR3, and F480/F535 for cygnet2 and Epac-S ${ }^{H 150}$ sensors. The pseudocolor images display the ratio value coded in hue and the fluorescence of the preparation coded in intensity.

Two-photon imaging was used to separate individual neurons for a precise quantification of the amplitude of the response (Figs. 1, 2). Ratio measurements were performed on a series of 5-10 consecutive image from the image stack, centered on the cell body. With cytosolic biosensors, when visible, the nucleus was excluded from the measurement. Wide-field imaging (Figs. $3 A-E$ ) also allowed the unambiguous identification of $D_{1}$ and $D_{2}$ MSNs, provided that the infection level was kept low and no fluorescence overlap between neighboring neurons was observed. The optical cross-contamination resulting from out-of-focus light was evaluated by the final response to CGS 21680 and SKF-38393, applied sequentially: cells were rejected from analysis if the crosscontamination was $>30 \%$. For cGMP imaging (Fig. $3 F, G$ ), the data were quantified as relative ratio change.

\section{Quantifications of cAMP signals}

The amplitudes of responses were quantified for each neuron as the fractional change in ratio from its own baseline and maximal final ratio response. Responses obtained from MSNs of the same type were averaged for each experiment (i.e., brain slice).

The free cAMP concentrations were estimated with the Epac-S ${ }^{H 150}$ biosensor from the ratio measurement using the Hill equation, with a $K_{\mathrm{d}}$ of $4.4 \mu \mathrm{M}$ and a Hill coefficient of 0.77 , as determined from Polito et al. (2013). The maximal response corresponding to biosensor saturation $\left(R_{\max }\right)$ was determined for each neuron at the end of the recording. This level was obtained by applying $13 \mu \mathrm{M}$ forskolin (FSK), a dose known to be sufficient to maximally phosphorylate the highly sensitive probe AKAR3 in MSNs. For cAMP biosensors, this $R_{\max }$ value was obtained with $200 \mu \mathrm{M}$ IBMX and $13 \mu \mathrm{M}$ forskolin.

The baseline cAMP level in control conditions was evaluated by inhibiting adenylyl cyclases with $200 \mu \mathrm{M}$ SQ22536, which resulted in a ratio decrease, measured in wide-field microscopy, of $-4.0 \%$ of the maximal ratio change. This decrease in baseline ratio was $-4.9 \pm 0.7$ and $-3.3 \pm 0.7(n=6, p<0.05$ with paired Student's $t$ test), respectively, in $D_{1}$ and $D_{2}$ MSNs. Assuming that adenylyl cyclase inhibition effectively decreased cAMP levels down to a level sufficient to reach the minimal ratio level $\left(R_{\text {min }}\right)$, these values suggest a baseline cAMP concentration in a range of $\sim 100 \mathrm{nM}$.

\section{Tissue preparation and immunofluorescence}

Mice, 8-10 weeks old, were treated with the drug for 60 min and then rapidly anesthetized with pentobarbital (500 $\mathrm{mg} / \mathrm{kg}$, i.p.; Sanofi-Aventis) and were transcardially perfused with $4 \%(\mathrm{w} / \mathrm{v})$ paraformaldehyde in $0.1 \mathrm{~m} \mathrm{PBS}, \mathrm{pH}$ 7.5. Brains were post-fixed overnight in the same solution and stored at $4^{\circ} \mathrm{C}$. The $30-\mu \mathrm{m}$-thick sections were cut with a vibratome and stored at $-20^{\circ} \mathrm{C}$ in a solution containing $30 \%(\mathrm{v} / \mathrm{v})$ ethylene glycol, $30 \%(\mathrm{v} / \mathrm{v})$ glycerol and $0.1 \mathrm{~m}$ sodium phosphate buffer, until they were processed for immunofluorescence. Sections were processed as described in Bertran-Gonzalez et al. (2009). Sodium fluoride $0.1 \mathrm{~mm}$ was included in all buffers and incubation solu- 
A

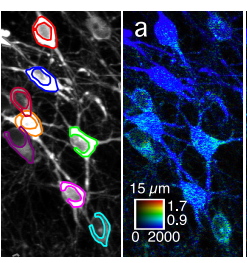

cAMP biosensor
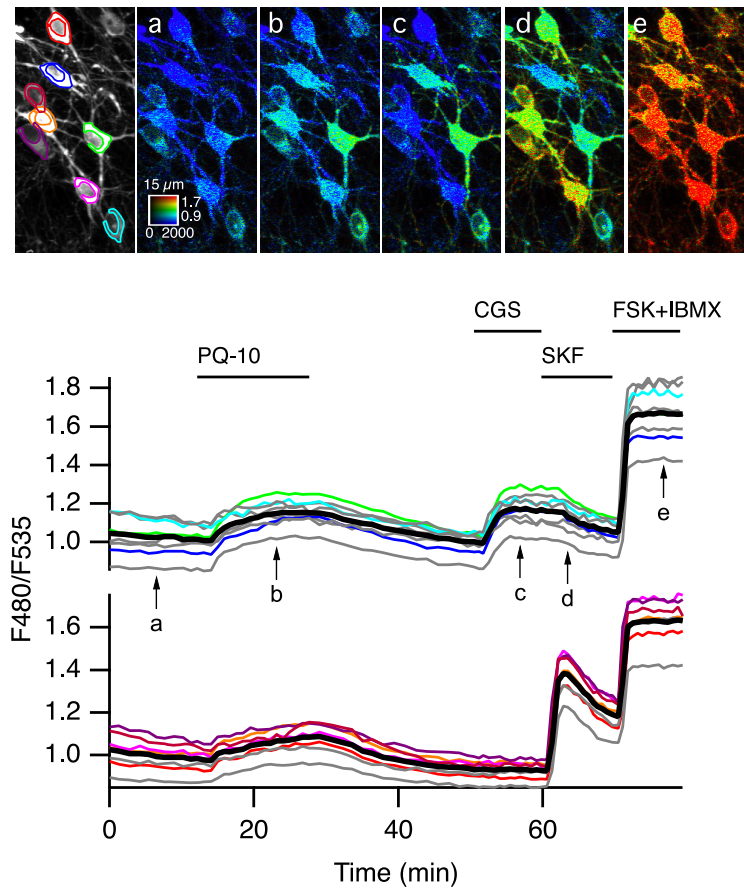

B

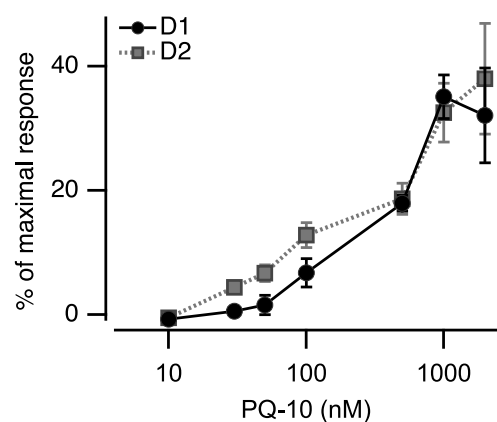

C
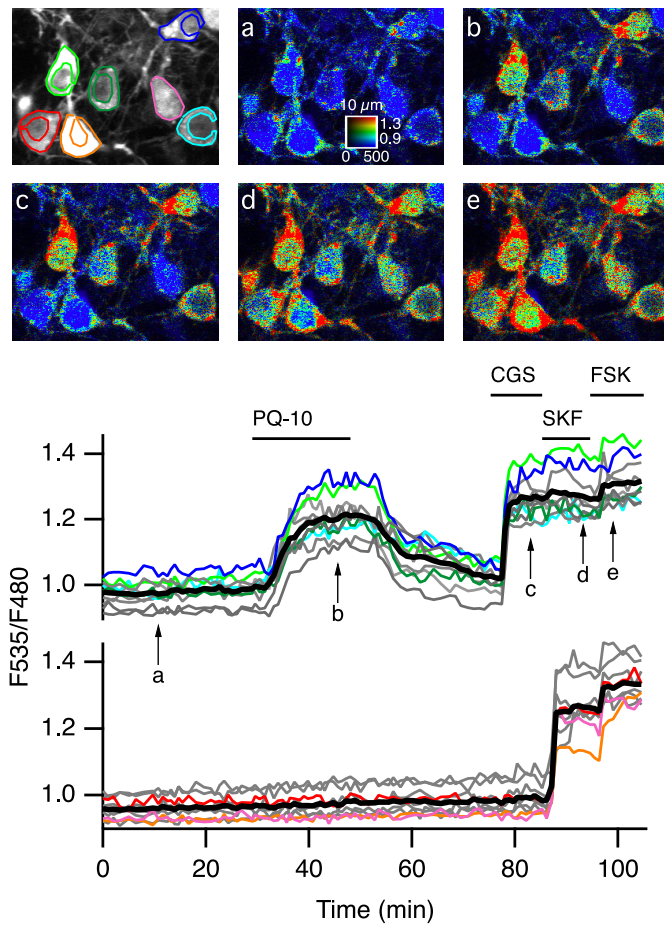

D

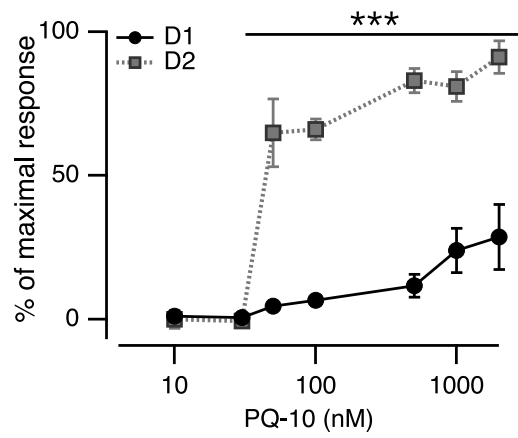

Figure 1. PDE10A inhibition increases cAMP levels in both in $D_{1}$ and $D_{2} M S N s$, and PKA-dependent phosphorylation only in $D_{2} M S N s$. $\boldsymbol{A}, \mathrm{MSNs}$ in a neostriatal mouse brain slice expressing the cAMP biosensor Epac-S ${ }^{\mathrm{H} 150}$ were imaged with two-photon microscopy during the application of PQ-10 (100 nM). Images (vertical projection of the image stack) show the raw fluorescence at $535 \mathrm{~nm}$ (left, in grayscale) and the ratio (in pseudocolor) indicating intracellular cAMP concentrations, at the times indicated by the arrows on the graph below. The calibration square in $\boldsymbol{A}$ indicates the spatial scale (the size of the square is indicated in micrometers), and shows the ranges of intensity (horizontally) and ratio (vertically). Each trace on the graph indicates the F480/F535 emission ratio measured in regions indicated by the color contour drawn on the raw image. Traces in gray correspond to regions that are not visible on these images. Traces are plotted in two groups according to their response to either CGS 21680, an adenosine $A_{2 A}$ receptor agonist (CGS, $1 \mu \mathrm{M})$, or SKF-38393, a $\mathrm{D}_{1}$-like receptor agonist (SKF, $\left.1 \mu \mathrm{M}\right)$. The thick black line represents the average of all the traces in a group. FSK $(13 \mu \mathrm{M})$ and IBMX $(200 \mu \mathrm{M})$ were applied at the end of the recording to determine the maximal response. $\boldsymbol{B}$, The same experiment was repeated for every PQ-10 concentration tested. No significant difference was found between $D_{1}$ and $D_{2}$ MSNs (two-way ANOVA: dose effect, $\mathrm{F}_{(6,54)}=40.91, p<10^{-4} ; \mathrm{D}_{1} / \mathrm{D}_{2}$ effect, $\mathrm{F}_{(1,54)}=2.56, p=0.115$; dose $\times \mathrm{D}_{1} / \mathrm{D}_{2}$ interaction, $F_{(6,54)}=0.625, p=0.709$ ). Error bars indicate the SEM. $\boldsymbol{C}$, Same as $\boldsymbol{A}$, except that the AKAR3 biosensor was used to monitor PKA-dependent phosphorylation, and the ratio was calculated as F535/F480. $\boldsymbol{D}$, Same as $\boldsymbol{B}$ for AKAR3 measurements. Data were analyzed with two-way ANOVA: dose effect, $F_{(6,38)}=28.31, p<10^{-4} ; D_{1} / D_{2}$ effect, $F_{(1,38)}=143.73, p<10^{-4}$; dose $\times D_{1} / D_{2}$ interaction, $F_{(6,38)}=9.23, p<10^{-4}$ Bonferroni's post hoc test, $* * * p<0.001$.

tions. Histone $\mathrm{H} 3$ phosphorylation was revealed with a rabbit polyclonal antibody against phospho-Ser10-H3 (1: 1000; catalog \#06570; Millipore) the specificity of which was confirmed in a previous study (Jordi et al., 2013). GFP was detected using chicken antibody against GFP (1:500; catalog \#A10262; Life Technologies). Following incubation with primary antibodies, sections were rinsed three times for $10 \mathrm{~min}$ in TBS and incubated for 45-60 min with goat Cy3-coupled (1:500; Jackson ImmunoResearch; Fig. 5 ) and goat A488 (1:500; Life Technologies; Fig. 6). Sec- 
tions were rinsed for 10 min twice in Tris-buffered saline and twice in Tris buffer $(0.25 \mathrm{M}$ Tris) before mounting in 1,4-diazabicyclo-[2. 2. 2]-octane (Sigma-Aldrich).

Single-labeled images (Fig. 6) were obtained with a Zeiss LSM780 Confocal Microscope. Double-labeled images (Fig. 5) were obtained with a Leica TCS SPE Confocal Microscope with laser lines at 496 and $561 \mathrm{~nm}$, acquiring in the 501-539 $\mathrm{nm}$ and 570-660 nm bands. All parameters were held constant for all sections from the same experiment.

\section{Statistics}

Data were analyzed with SPSS statistical software version 22.0. Normality in variable distributions and homogeneity of variances across groups were assessed with the Shapiro-Wilk and Levene tests, respectively. Variables that failed any of these tests were analyzed with nonparametric statistics using the Kruskal-Wallis ANOVA on ranks followed by Mann-Whitney rank sum test with a DunnSidak adjustment test for pairwise multiple comparisons. Variables that passed the normality test were analyzed with ANOVA followed by Bonferroni post hoc test for multiple comparisons or by Student's $t$ test for comparing two groups. Paired data were analyzed with a Student's $t$ test. A $p$ value of $<0.05$ was used as a cutoff for statistical significance. All error bars represent the SEM; $n$ indicates the number of experiments (i.e., the number of brain slices tested), with at least four neurons of each type in each experiment. All experiments were performed on at least three different brain slices from at least two animals.

\section{Drugs}

SKF-38393 hydrobromide, CGS 21680 hydrochloride, 1-methyl-3-isobutylxanthine (IBMX), rolipram, papaverine, roscovitine, okadaic acid, cantharidin, gabazine, CNQX, APV, and forskolin were obtained from Tocris Cookson. TTX was from Latoxan. PQ-10, MP-10, and roflumilast were a gift from Janssen Pharmaceuticals. TP-10 was provided by Pfizer through the Compound Transfer Program.

\section{Results}

\section{PDE10A inhibition reveals a tonic cAMP production in both $D_{1}$ and $D_{2}$ MSNs}

Since both $D_{1}$ and $D_{2}$ MSNs express high levels of PDE10A protein (Nishi et al., 2008), we used biosensorimaging approaches to compare the effects of PDE10A inhibition on the cAMP/PKA signaling cascade in $D_{1}$ and $D_{2}$ MSNs. First, we monitored changes in intracellular cAMP concentrations with two-photon microscopy in striatal brain slices expressing Epac- $S^{H 150}$. At the end of every experiment, an agonist of adenosine $A_{2 A}$ receptors (CGS 21680, $1 \mu \mathrm{M}$ ) and an agonist of dopamine $\mathrm{D}_{1}$ receptors (SKF-38393, $1 \mu \mathrm{M}$ ) were applied sequentially, triggering a positive cAMP response in $D_{2}$ and $D_{1}$ MSNs, respectively, thereby functionally identifying MSN subtypes. The final application of the general adenylyl cyclase activator FSK $(13 \mu \mathrm{M})$ together with the nonselective phosphodiesterase inhibitor IBMX $(200 \mu \mathrm{M})$ produced the maximal ratio response used for normalization.
PDE10A inhibition with PQ-10 (100 nM) increased cAMP levels in all MSNs (Fig. 1A) in a dose-dependent manner. This dose dependency was not statistically different between $D_{1}$ and $D_{2}$ MSNs (Fig. 1B). At the highest doses (1 and $2 \mu \mathrm{M}$ ), cAMP responses reached $\sim 35 \%$ of the maximal response to FSK plus IBMX, which corresponds to a concentration of free CAMP of $\sim 2 \mu \mathrm{M}$ (see Materials and Methods for details on the estimation of cAMP concentrations). These experiments showed that, in the basal condition, CAMP is tonically produced in striatal slices and that PDE10A contributes significantly to its degradation.

\section{PDE10A inhibition increases the phosphorylation of a PKA target exclusively in $\mathrm{D}_{\mathbf{2}}$ MSNs}

We then analyzed the effects of PQ-10 on PKAdependent phosphorylation levels using the PKA biosensor AKAR3. As for CAMP imaging, MSNs were identified at the end of each experiment by their response to either $A_{2 A}$ or $D_{1}$ receptor agonist. The maximal AKAR3 response was elicited by FSK. Although the increase in free cAMP concentration was similar in $D_{1}$ and $D_{2}$ MSNs (Fig. $1 A, B$ ), the resulting PKA-dependent phosphorylation levels were completely different (Fig. 1C): PQ-10 (100 nM) strongly increased the emission ratio of AKAR3 in the $D_{2}$ MSNs (66 $\pm 4 \%$ of the maximal response to FSK, $n=4)$; whereas, in $D_{1}$ MSNs, the ratio remained at a much lower level $6 \pm$ $2 \%)$. These results indicated a significantly higher phosphorylation of AKAR3 in $D_{2}$ than in $D_{1}$ MSNs in response to $P Q-10$. The effect of $P Q-10$ on AKAR3 ratio in $D_{2} M S N s$ was steeply dose dependent with a maximal effect reached at $<100 \mathrm{~nm}$ (Fig. 1D). In stark contrast to $D_{2}$ MSNs, even high doses of $P Q-10$, which increased cAMP to the same levels in $D_{1}$ and $D_{2}$ MSNs (Fig. $1 B$ ), only produced a very small effect on AKAR3 phosphorylation in $D_{1}$ MSNs (Fig. 1D). These experiments thus revealed a much stronger effect of CAMP on PKA-dependent phosphorylation in $D_{2}$ than in $D_{1}$ MSNs.

PDE10A may be addressed differentially in the cytoplasm and membranes (Kotera et al., 2004; Charych et al., 2010), and cAMP dynamics could differ in subcellular domains of different geometry, like dendrites (Castro et al., 2010). An increase in AKAR3 ratio was observed exclusively in the dendritic branches that responded to the $A_{2 A}$ agonist, whereas dendrites, which responded to the $D_{1}$ agonist, showed no response to $100 \mathrm{~nm} P Q-10$ (Fig. 2A). This is consistent with other biosensor recordings in which dendrites of $D_{1}$ MSNs also exhibited no baseline response to PDE10A inhibition (Yagishita et al., 2014).

Once activated, PKA can translocate to the nucleus and phosphorylate a number of nuclear proteins. We examined whether the differential response to PQ-10 also existed in the nucleus. Using the nuclear AKAR2-NLS biosensor, we found that PDE10A inhibition induced a strong ratio increase in $D_{2}$ MSNs, while $D_{1}$ MSNs remained unresponsive (Fig. $2 B$ ). These results showed that $P Q-10$ efficiently increased AKAR3 phosphorylation in the cytoplasm and nucleus of $D_{2}$ but not $D_{1} M S N s$, whereas they had a similar and selective effect on cAMP production in the two cell types. 
A
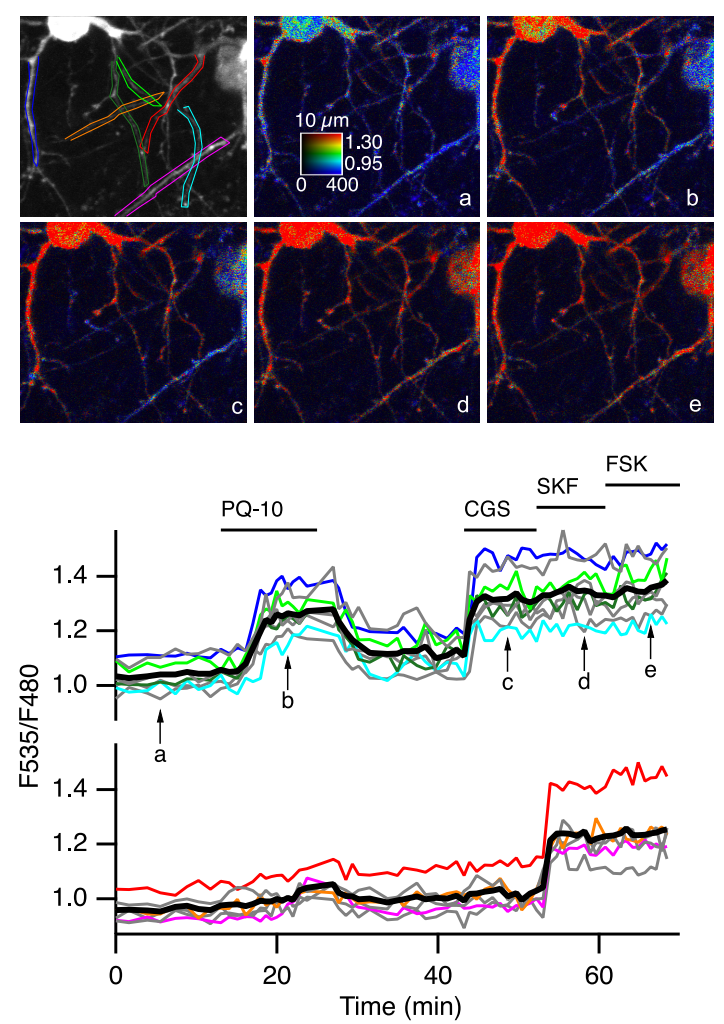

B
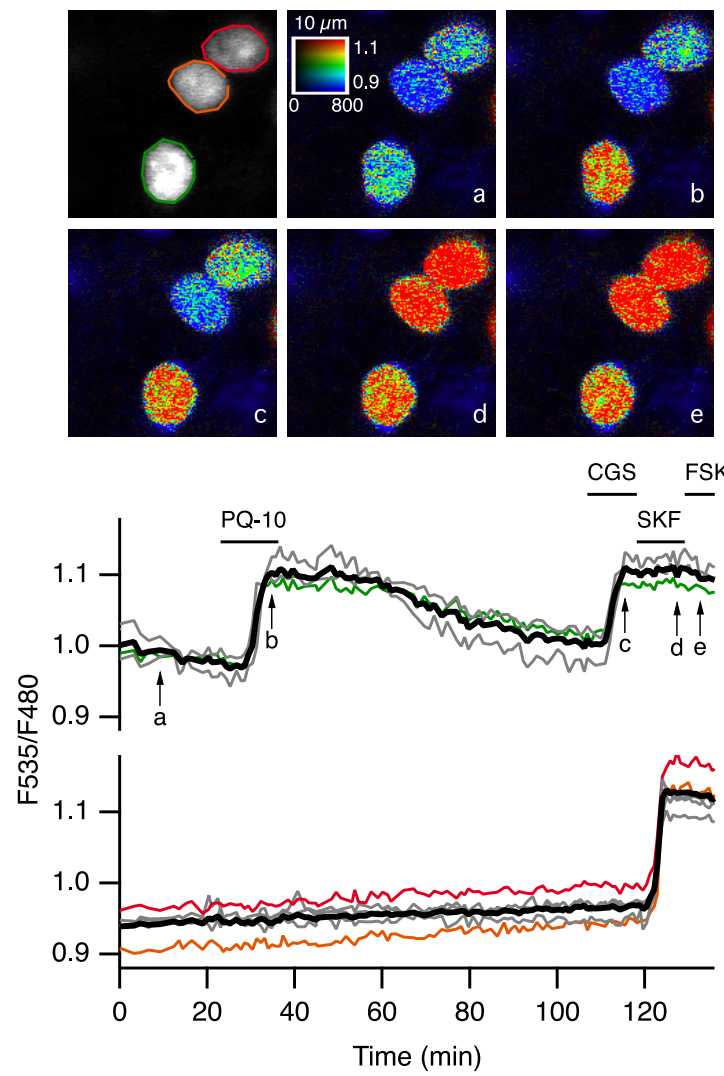

Figure 2. PDE10A inhibition triggers positive PKA responses in dendrites and nuclei preferentially in $D_{2}$ MSNs. $\boldsymbol{A}, \boldsymbol{B}$, Brain slices expressed the PKA sensor AKAR3 $(\boldsymbol{A})$ or AKAR2-NLS $(\boldsymbol{B})$ and were imaged by two-photon microscopy during the application of PQ-10 (100 nM). Images show the raw fluorescence at $535 \mathrm{~nm}$ (left in grayscale) and the ratio (in pseudocolor) indicating the PKA-dependent phosphorylation level of the biosensor, at the times indicated by the arrows on the graph below. The calibration square in $\boldsymbol{A}$ indicates the spatial scale (above, in micrometers), and shows the ranges of intensity (horizontally) and ratio (vertically). Each trace on the graph indicates the F535/F480 emission ratio measured on regions indicated by the color contour drawn on the raw image. Traces are plotted in two groups according to their response to either CGS 21680 (CGS, $1 \mu \mathrm{M}$ ) or SKF-38393 (SKF, $1 \mu \mathrm{M})$. The thick black line represents the average of all the traces in a group. FSK $(13 \mu \mathrm{M})$ was applied at the end of the recording to determine the maximal response.

\section{PDE10A inhibition effects are antagonized by $D_{2}$ receptors and independent of $A_{2 A}$ receptors}

One feature of striatopallidal MSNs is the coexpression of $D_{2}$ dopamine and $A_{2 A}$ adenosine receptors, negatively and positively coupled to adenylyl cyclase, respectively (Schiffmann et al., 1991; Schiffmann and Vanderhaeghen, 1993; Ferré et al., 1997; Svenningsson et al., 1999; Bateup et al., 2008; Bertran-Gonzalez et al., 2009). Application of the $D_{2}$ receptor agonist quinpirole $\left(\begin{array}{ll}1 & \mu \mathrm{M}\end{array}\right)$ completely reversed the $\mathrm{PQ}-10$-induced AKAR3 response in $\mathrm{D}_{2}$ MSNs, monitored with wide-field microscopy (Fig. $3 A)$. Application of quinpirole alone had no effect on the basal AKAR3 ratio but prevented positive responses to PQ-10 in $D_{2}$ MSNs with $11 \pm 3 \%(n=5)$ of the maximal FSK response in $D_{2}$ MSNs compared with $9 \pm 2 \%$ in $D_{1}$ MSNs (Fig. 3B). These results showed that the activation of $D_{2}$ receptors opposed the effect of $P Q-10$ in $D_{2}$ MSNs, most likely via Gi-mediated inhibition of the tonic adenylyl cyclase activity. These experiments also further confirmed that the positive AKAR3 response to $P Q-10$ was specific to MSNs expressing $D_{2}$ receptors.

We then determined whether the effect selectivity for $D_{2}$ MSNs was a particular property of PQ-10 or was also observed with other PDE10A inhibitors. The effects of MP-10 (100 nM) and papaverine $(1 \mu \mathrm{M})$ on AKAR3 ratio were similar (Fig. 3C,D), inducing an AKAR3 ratio increase selectively in $D_{2}$ MSNs. TP-10 also produced the same response profile (see below). In contrast, PDE4 inhibitors (rolipram, $100 \mathrm{~nm}, n=4$; and roflumilast, $1 \mu \mathrm{M}, n=4$ ) had no effect on basal AKAR3 ratio (data not shown).

As $D_{2}$ MSNs express adenosine $A_{2 A}$ receptors, we examined whether the tonic presence of extracellular adenosine in our brain slice preparation activated adenylyl cyclase and might be responsible for the positive response to PQ-10 recorded specifically in these MSNs. When $\mathrm{A}_{2 \mathrm{~A}}$ receptors were blocked with $\mathrm{SCH} 58261$ (100 $n M), P Q-10$ still elicited positive responses in $D_{2}$ MSNs (Fig. 3E). In contrast, SCH 58261 blocked the responses 
A

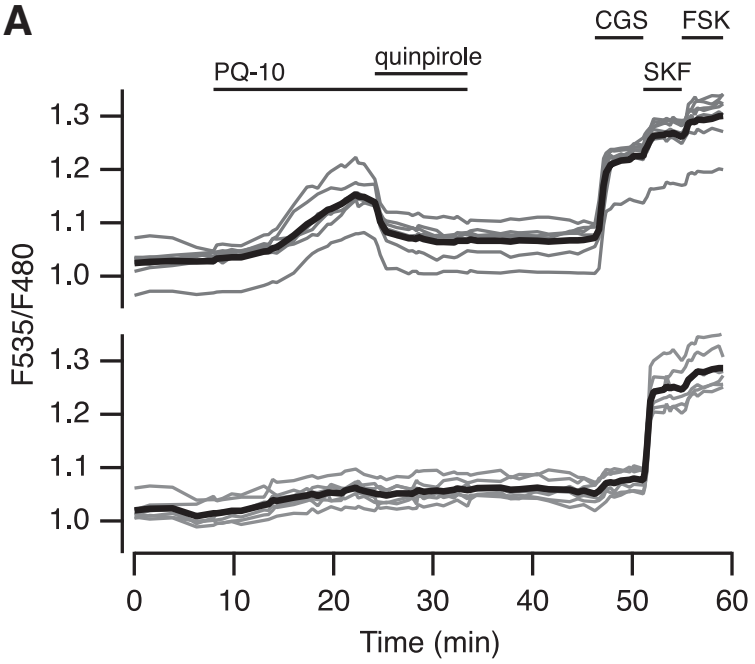

C

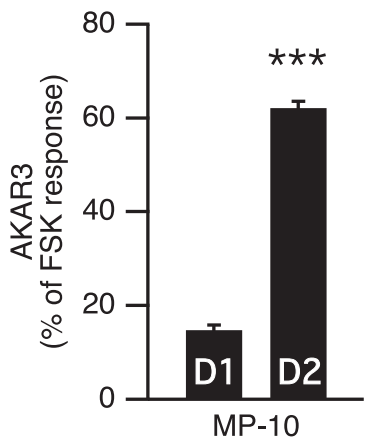

D

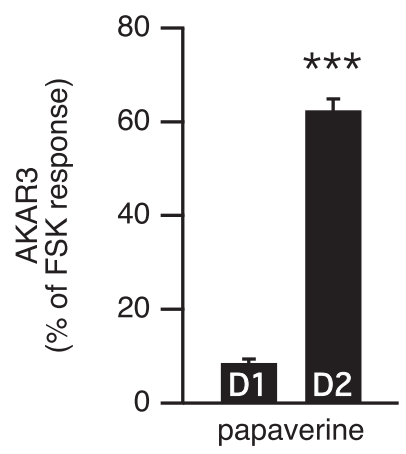

B

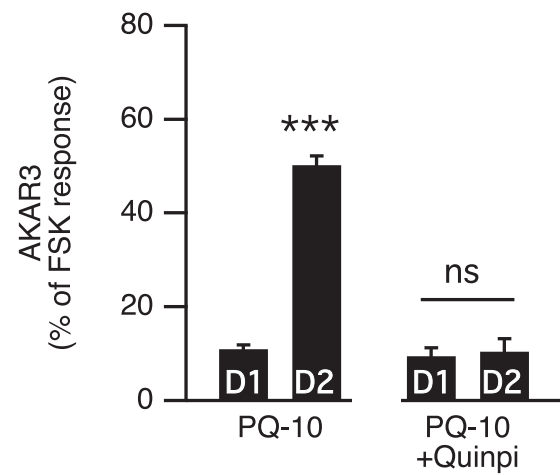

E
F

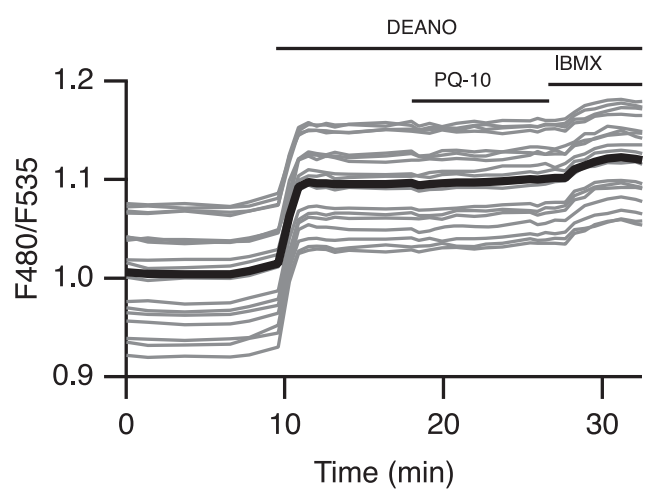

G

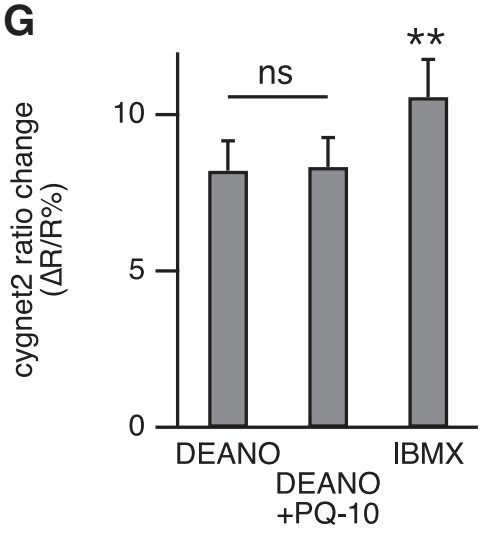

Figure 3. $\boldsymbol{A}$, Activation of $\mathrm{D}_{2}$ dopamine receptors suppressed the effect of PDE10A inhibition on AKAR3 ratio. Each trace on the graph indicates the ratio measurement on MSNs expressing AKAR3 and identified as $D_{1}$ or $D_{2}$ according to their response to either SKF-38393 (SKF, $1 \mu \mathrm{M})$ or CGS 21680 (CGS, $1 \mu \mathrm{M})$, respectively. The thick black line represents the average of all the traces in a group. Bath application of the agonist of dopamine $D_{2}$ receptors quinpirole $(1 \mu \mathrm{m})$ reversed the response to $P Q-10(100 \mathrm{nM})$. $B$, $D_{2}$ receptor activation prevented the response to PDE10A inhibition: the effect of PQ-10 was measured in the presence of the $D_{2}$ agonist quinpirole $(1 \mu \mathrm{M})$. No statistically significant difference $(p>0.05)$ was found between $D_{1}$ and $D_{2} M S N s(n=5)$. The effect of $P Q-10$ is displayed for comparison on the left (same data as in Fig. 4E). $\boldsymbol{C}, \boldsymbol{D}$, Other PDE10A inhibitors also increased the AKAR3 ratio preferentially in $\mathrm{D}_{2}$ MSNs: MP-10 $(\boldsymbol{C} ; 100 \mathrm{nM}, n=9)$ and papaverine $(\boldsymbol{D} ; 1 \mu \mathrm{M}, n=5)$ both increased the AKAR3 ratio selectively in $D_{2}$ MSNs. $\boldsymbol{E}, \mathrm{PQ}-10$ increased AKAR3 ratio selectively in $\mathrm{D}_{2}$ MSNS even when adenosine $A_{2 A}$ receptors were inhibited with $100 \mu \mathrm{M}$ SCH $58261(n=4)$. B-E, Statistical differences were tested with paired Student's $t$ test. $* * * p<0.001$. $\boldsymbol{F}$, PDE10A inhibition had no effect on cGMP levels measured with the cGMP sensor cygnet2. The NO donor DEANO (100 $\mu \mathrm{M})$ increased the ratio; after reaching a steady-state level, PQ-10 (1 $\mu \mathrm{M})$ was added; at the end of the recording, the maximal ratio response was elicited by DEANO plus 
continued

IBMX (200 $\mu \mathrm{M})$. G, No difference was measured when comparing the response with DEANO alone and DEANO with PQ-10, while IBMX produced a significant increase. The data expressed as the mean \pm SEM were analyzed by repeated-measures one-way ANOVA $F_{(1,5)}$ $=11,224, p<0.001, n=6$, followed by Bonferroni's post hoc test: $* * p<0.01)$. $\boldsymbol{A}-\mathbf{G}$, Brain slices were imaged with wide-field microscopy. All data are expressed as the mean \pm SEM.

to the $A_{2 A}$ agonist CGS 21680 (data not shown). These results showed that tonic activation of $A_{2 A}$ receptors was not required for the phosphorylation response to $P Q-10$ in $D_{2}$ MSNs. We then examined whether the phosphorylation signal involved endogenous neuronal activity, or required the glutamate and GABA which may be present in the brain slice. This was not the case since, in the presence of blockers of voltage-gated sodium channels (TTX, $100 \mathrm{nM})$, calcium channels $\left(\mathrm{CdCl}_{2}, 200 \mu \mathrm{M}\right)$, non-NMDA receptors (CNQX, $10 \mu \mathrm{M}$ ), NMDA receptors (APV, $10 \mu \mathrm{M}$ ), and $\mathrm{GABA}_{\mathrm{A}}$ receptors (SR 95531, $1 \mu \mathrm{M}$ ), the selective effect of PQ-10 on $D_{2}$ MSNs was still present $(25 \pm 3$ vs $71 \pm 10$ of the maximal FSK response in $D_{1}$ and $D_{2} M S N s$, respectively; $n=3$, paired Student's $t$ test; data not shown).

Since PDE10A also degrades cGMP and PDE10A inhibition was shown to increase cGMP levels and affect synaptic transmission in vivo (Siuciak et al., 2006; Schmidt et al., 2008; Grauer et al., 2009; Padovan-Neto et al., 2015), we used wide-field imaging of the cGMP biosensor cygnet2 (Honda et al., 2001) to determine whether PDE10A also regulated cGMP in MSNs. PQ-10 (1 $\mu \mathrm{M})$ had no effect on the baseline cGMP levels $(n=4, p=$ 0.44 , one-sample Student's $t$ test). In addition, PQ-10 (1 $\mu \mathrm{M})$ had no effect on the cGMP steady-state level obtained with the nitric oxide (NO) donor DEANO (Diethylamine nitric oxide, $100 \mu \mathrm{m} ; n=6$; Fig. $3 F$ ), while the nonspecific phosphodiesterase inhibitor IBMX produced a significant ratio increase. These results indicated that in our conditions PDE10A inhibition does not significantly affect cGMP levels in MSNs.

\section{Different responsiveness of $D_{1}$ and $D_{2} M S N s$ is abolished by protein phosphatase inhibition}

The difference between $D_{1}$ and $D_{2}$ MSNs in the phosphorylation level of AKAR3 could result from differences in the rate of phosphorylation by PKA, dephosphorylation by phosphatases, or both. A difference in PKA levels is unlikely because immunostaining of catalytic subunits in the striatum did not reveal major differences between cells (Yang et al., 2014). Since AKAR3 biosensor responses to PKA activation are reversed by the action of endogenous protein phosphatases (Gervasi et al., 2007), we investigated the role of protein phosphatases in the different responsiveness of $D_{1}$ and $D_{2}$ MSNs to PDE10A inhibitors.

Cantharidin $(30 \mu \mathrm{M})$, a nonselective inhibitor of PP-1 and PP-2A, had no effect by itself on the AKAR3 emission ratio (Fig. 4A). However, when PQ-10 (100 nM) was applied in the bath (Fig. 4A), the AKAR3 ratio increased in virtually all $D_{1}$ and $D_{2}$ MSNs $(79 \pm 10 \%$ of the FSK response, $n=5$ ). Since these responses did not return to the baseline after drug washout, it was impossible to distinguish between $D_{1}$ and $D_{2} M S N s$, and all MSNs were pooled (Fig. 4F, gray color bar). To identify which phosphatase subtype was involved in the response, we used fostriecin (200 nM), a selective inhibitor of PP-2A (Swingle et al., 2009). We observed no effect of this inhibitor alone on basal AKAR3 ratio, and it did not alter the selective response to $P Q-10$ in $D_{2}$ MSNs (Fig. 4B). These results showed that PP-2A was not involved in the different responsiveness of $D_{1} / D_{2}$ and rather suggested the involvement of PP-1.

\section{PP-1 regulation by DARPP-32 is necessary for the selective responsiveness of $D_{2}$ MSNs to PDE10A inhibition}

DARPP-32 is expressed at high levels in both types of MSNs and constitutes a powerful and specific inhibitor of PP-1 when it is phosphorylated at Thr34 (Hemmings et al., 1984). We used a knock-in mutant mouse line in which Thr34 is replaced by an alanine (T34A; Svenningsson et al., 2003). In T34A mice, the effect of PQ-10 on AKAR3 was strongly reduced in $\mathrm{D}_{2}$ MSNs (14 $\pm 2 \%, n=13,6$ mice), whereas, as in wild-type mice, no effect was observed in $D_{1}$ MSNs (8 $\pm 1 \%$; Fig. 4C,E). Normal responses to $D_{1}$ or $A_{2 A}$ stimulations were observed at the end of the recording. The phosphatase inhibitor cantharidin unmasked the response to $P Q-10$ in all MSNs of the DARPP-32 T34A mice (Fig. 4F), confirming that, upon inhibition of PP-1, PQ-10 was still capable of increasing the AKAR3 response in these mutant mice. Together, these results show that the inhibition of PP-1 by DARPP-32 is necessary for the difference in responsiveness of $D_{1}$ and $D_{2}$ MSNs.

DARPP-32 also inhibits PKA activity when it is phosphorylated at Thr75 by Cdk5 (Bibb et al., 1999; Nishi et al., 2000). A higher phosphorylation level of this residue in $D_{1}$ MSNs could be responsible for a weaker PKA activity in these neurons. However, in a knock-in mutant mouse line with a Thr75-to-alanine mutation (DARPP-32 T75A; Svenningsson et al., 2003), the profile of the AKAR3 response to $P Q-10$ was the same as that in wild-type mice (Fig. $4 D, E)$. Moreover, the Cdk5 inhibitor roscovitine (10 $\mu \mathrm{M})$ had no effect on the $D_{1} / D_{2}$ imbalance in the response to PQ-10 (Fig. 4G), ruling out the involvement of Thr75 of DARPP-32 as a critical determinant for the lack of PQ-10dependent AKAR3 responses in $D_{1}$ MSNs.

\section{In vivo PDE10A inhibition selectively induces histone H3 phosphorylation in $D_{2}$ MSNs of the dorsomedial striatum}

Our results showed a marked difference in the responsiveness of $D_{1}$ and $D_{2}$ MSNs to PDE10A inhibitor in slices. We then investigated whether the $D_{1} / D_{2}$ imbalance could also be observed in vivo by monitoring phospho-histone $\mathrm{H} 3$ at Ser10 residue (PH3), a substrate for several protein 
A

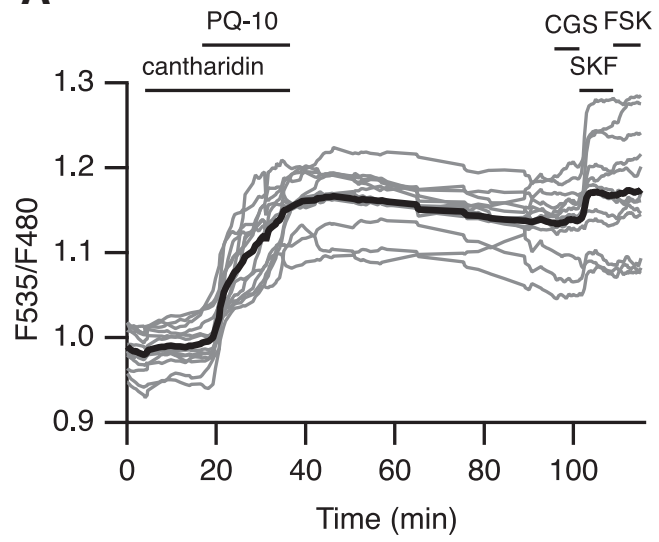

C

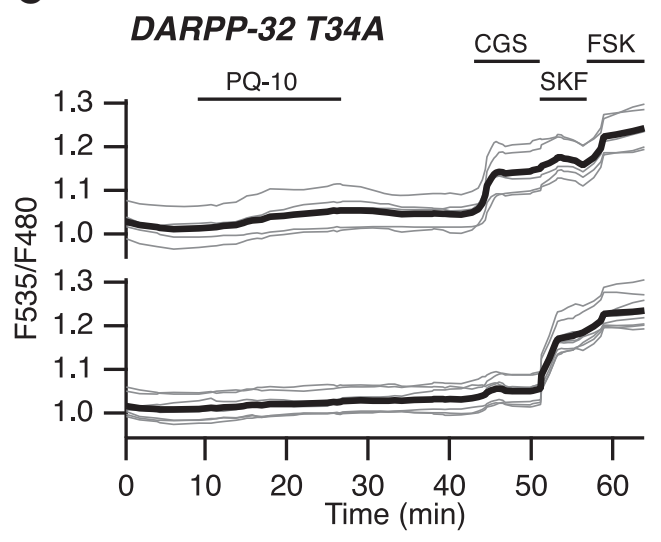

E

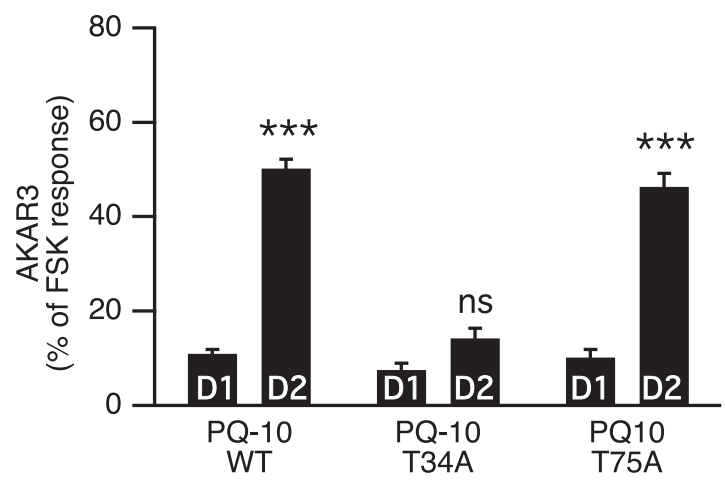

B

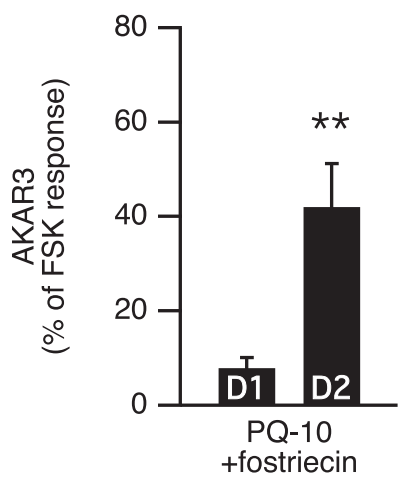

D

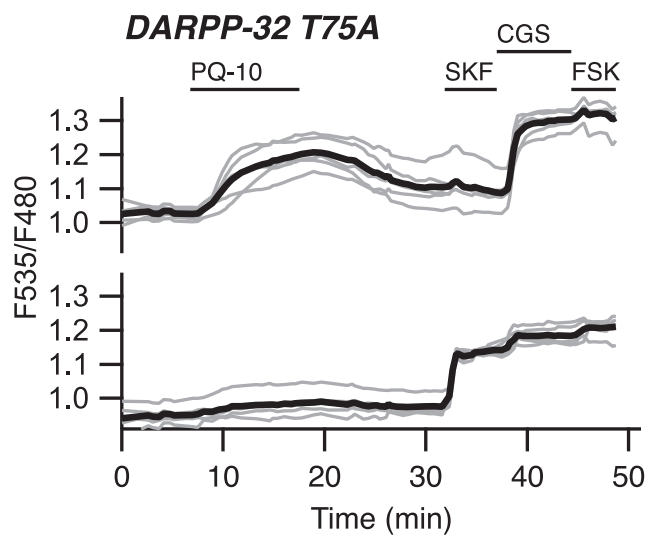

F

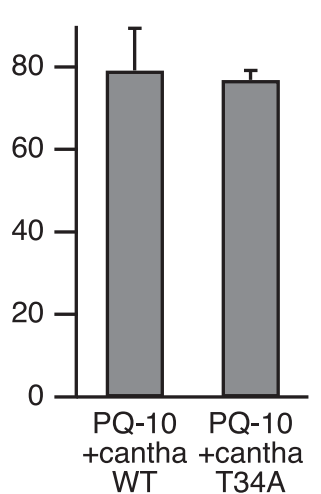

G

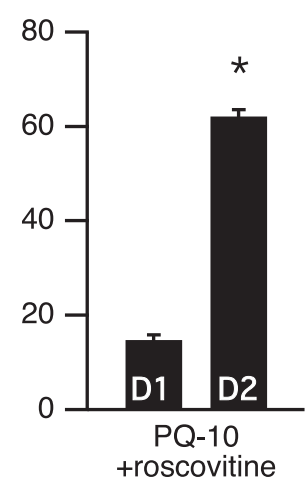

Figure 4. DARPP-32-mediated phosphatase inhibition favors PKA signaling in $D_{2} M S N s$. $A$, PP-1 and PP-2A were inhibited with cantharidin. Cantharidin (30 $\mu \mathrm{m})$ alone did not change the basal ratio but strongly increased the AKAR3 response to PQ-10 (100 nM) in all MSNs. These responses were not reversible, making the final identification of $D_{1}$ and $D_{2} M S N s$ impossible (gray bars in $\boldsymbol{F}$, which represent the responses of all MSNs). $\boldsymbol{B}, \mathrm{D}_{2} \mathrm{MSNs}$ responded selectively to PQ-10 (100 nM) even when the PP-2A inhibitor fostriecin (200 nм) was applied ( $n=4$, paired Student's $t$ test; $* * \mathrm{p}<0.01)$. $\boldsymbol{C}-\boldsymbol{E}$, Mutation of the Thr34 to Ala in DARPP-32 (DARPP-32 T34A) strongly reduced the effect of $P Q-10(100 \mathrm{~nm})$ in $D_{2}$ MSNs, whereas the selective effect of $P Q-10$ on $D_{2}$ MSNs remained in brain slices from animals bearing the Thr75 to Ala mutation in DARPP-32 (DARPP-32 T75A). $\boldsymbol{C}, \boldsymbol{D}$, Representative experiments performed with DARPP-32 T34A $(\boldsymbol{C})$ and DARPP-32 T75A $(\boldsymbol{D})$ knock-in mice. Each trace on the graph indicates the ratio measurement on MSNs expressing AKAR3 and is identified as $D_{1}$ or $D_{2}$ according to their response to either SKF-38393 (SKF, $\left.1 \mu \mathrm{M}\right)$ or CGS 21680 (CGS, $1 \mu \mathrm{M})$, respectively. The thick black line represents the average of all the traces in each group. $\boldsymbol{E}$, The data expressed as the mean \pm SEM were analyzed by two-way ANOVA: genotype effect, $\mathrm{F}_{(2,72)}=71.12, p<10^{-4} ; \mathrm{D}_{1} / \mathrm{D}_{2}$ effect, $\mathrm{F}_{(1,72)}=333.07, p<10^{-4}$; genotype $\times D_{1} / D_{2}$ interaction, $F_{(2,72)}=49.53, p<10^{-4}$. Bonferroni's post hoc test: ***p $<0.001$. $\boldsymbol{F}$, In wild-type (WT) mice and DARPP-32 T34A mutants, and in the presence of cantharidin (30 $\mu \mathrm{M})$, all MSNs responded to PQ-10 (100 nM) with an increase in AKAR3 ratio such that $D_{1}$ and $D_{2}$ MSNs could not be distinguished ( $n=5$ for both). No significant difference was obtained between 
continued

wild-type and DARPP-32 T34A mutant (unpaired Student's $t$ test, $p>0.05)$. G, $D_{2}$ MSNs responded selectively to PQ-10 (100 nM) even when the Cdk5 inhibitor roscovitine $(10 \mu \mathrm{M})$ was applied $(n=4$, paired Student's $t$ test; $* \mathrm{p}<0.05)$.

kinases including PKA (Nowak and Corces, 2004). We used transgenic mice in which $\mathrm{D}_{2}$ MSNs are identified by GFP fluorescence (drd2-EGFP mice; Gong et al., 2003; Bertran-Gonzalez et al., 2008) and monitored PH3 by immunofluorescence. In these in vivo experiments, we studied the effects of TP-10 (3 mg/kg, i.p.), a PDE10A inhibitor known to produce clear behavioral effects (Schmidt et al., 2008). At this dose, TP-10 induced a large increase in the number of $\mathrm{PH} 3$-positive neurons in the striatum 60 min after treatment, compared with vehicle treatment. Quantification showed that $93 \%$ of the PH3immunoreactive neurons were GFP positive $\left(D_{2} M S N s\right)$ in the dorsomedial striatum, whereas in lateral parts of the striatum both GFP-negative and GFP-positive $D_{2}$ MSNs exhibited PH3 immunoreactivity (Fig. $5 A-C$ ). In the nucleus accumbens, a sparse and irregular labeling was observed in the shell region, and no immunoreactivity was detected in the core. In all striatal regions, no $\mathrm{PH} 3 \mathrm{immu}-$ noreactivity was observed in large neurons expressing low levels of GFP, presumably corresponding to cholinergic interneurons.

Since in vivo the selective effects of TP-10 on $D_{2}$ MSNs was observed in the dorsomedial, but not the dorsolateral striatum, we performed a set of experiments in brain slices to compare medial and lateral dorsal striatum using the same inhibitor. The AKAR3 responses to TP-10 (100 nM) were similar, with a strong effect of TP-10 in $D_{2}$ MSNs but not in $\mathrm{D}_{1}$ MSNs (Fig. 5D,E). Altogether, these experiments showed that PDE10A exerts selective effects on $D_{2}$ MSNs in striatal slices and that this selectivity is maintained in vivo in the dorsomedial striatum.

DARPP-32 is required for the in vivo effects of TP-10 Our experiments in striatal slices showed that the inhibition of PP-1 by DARPP-32 phosphorylated on Thr34 was necessary for the selective responsiveness to PDE10A inhibition on AKAR phosphorylation. We then investigated whether the effects of PDE10A inhibition in vivo also depended on the phosphorylation of DARPP-32 at Thr34. T34A knock-in and wild-type littermates were treated with TP-10 (3 mg/kg, i.p.) or vehicle (four animals for each condition) and brain sections analyzed by immunofluorescence for PH3 60 min after injection. Whereas wild-type littermates strongly responded to TP-10, the effect of TP-10 was completely abolished in the DARPP-32 T34A mutant mice in all regions of the striatum (Fig. $6 A, B$ ). These experiments clearly showed that Thr34 in DARPP-32 was required for the effects of PDE10A inhibitor on $D_{1}$ and $D_{2} M S N s$ in both the dorsomedial and dorsolateral striatum in vivo.

\section{Discussion}

Our study shows that although PDE10A is expressed and functional in all types of MSNs, its inhibition in striatal slices produces a higher PKA-dependent protein phos- phorylation response in $D_{2}$ MSNs than in $D_{1}$ MSNs. We provide evidence that this difference is present in all striatal regions in brain slices and in the dorsomedial striatum of adult mice in vivo. Moreover, we show that the regulation of PP-1 activity by DARPP-32 is required for these specific effects of PDE10A inhibitors. These observations provide novel insights into the regulation of the CAMP/PKA pathway in the two populations of MSNs and the possible antipsychotic action of PDE10A inhibitors.

PDE10A is one of the enzymes specifically enriched in the striatum (Seeger et al., 2003; Coskran et al., 2006; Heiman et al., 2008; Lakics et al., 2010; Kelly et al., 2014), and the data reported here show that PDE10A plays an important role in degrading basally produced CAMP in both $D_{1}$ and $D_{2} M S N s$. MSNs thus contrast with pyramidal neurons of the prefrontal cortex in which basal cAMP is predominantly controlled by PDE4 (Castro et al., 2010). Although PDE4B is also expressed in $\mathrm{D}_{2}$ MSNs (Nishi et al., 2008), biosensor imaging of the somatic cytoplasm did not reveal significant effects of its inhibition in MSNs in our conditions.

PDE10A inhibition showed no effect on basal or stimulated cGMP production. A similar lack of effect of PDE10A inhibitors on cGMP has already been reported in brain slice preparations (Nishi et al., 2008). PDE10A thus differs from PDE1 and PDE2, other dual-specificity PDEs expressed in MSNs, which were shown in striatal homogenates to be the major PDEs involved in the control of cGMP levels (Russwurm et al., 2015). Using biosensorimaging techniques, PDE2 was also shown to be the main PDE that regulated stimulated CGMP, while also regulating CAMP in a cGMP-dependent manner (Polito et al., 2013). In vivo, PDE10A inhibition was shown to increase cGMP levels and to affect synaptic transmission (Siuciak et al., 2006; Schmidt et al., 2008; Grauer et al., 2009; Padovan-Neto et al., 2015), and why this effect was not observed in brain slices remains to be determined. One hypothesis to explain this discrepancy might be that, in vivo, PDE10A inhibitors recruit nitric oxide synthasepositive striatal interneurons through a global increase in network activity.

While $D_{1}$ and $D_{2}$ MSNs share a number of cellular features, more detailed studies revealed subtle differences (Valjent et al., 2009), such as different excitability profiles (Gertler et al., 2008; Threlfell et al., 2009). Differences were also reported at the level of PKA-dependent phosphorylation of $\mathrm{GABA}_{A}$ receptors and DARPP-32, which were higher in $D_{2}$ MSNs than in $D_{1}$ MSNs (Janssen et al., 2009; Nishi et al., 2008). Our work reveals a possible basis for these $D_{1} / D_{2}$ differences, which lies at the level of DARPP-32-mediated PP-1 regulation. In $\mathrm{D}_{1} \mathrm{MSNs}$, the Thr34 of DARPP-32 is in a lower phosphorylation state than in $\mathrm{D}_{2}$ MSNs and, thus, the PP- 1 activity reverts PKA target sites to the dephophorylated state (Fig. 7). This 
A
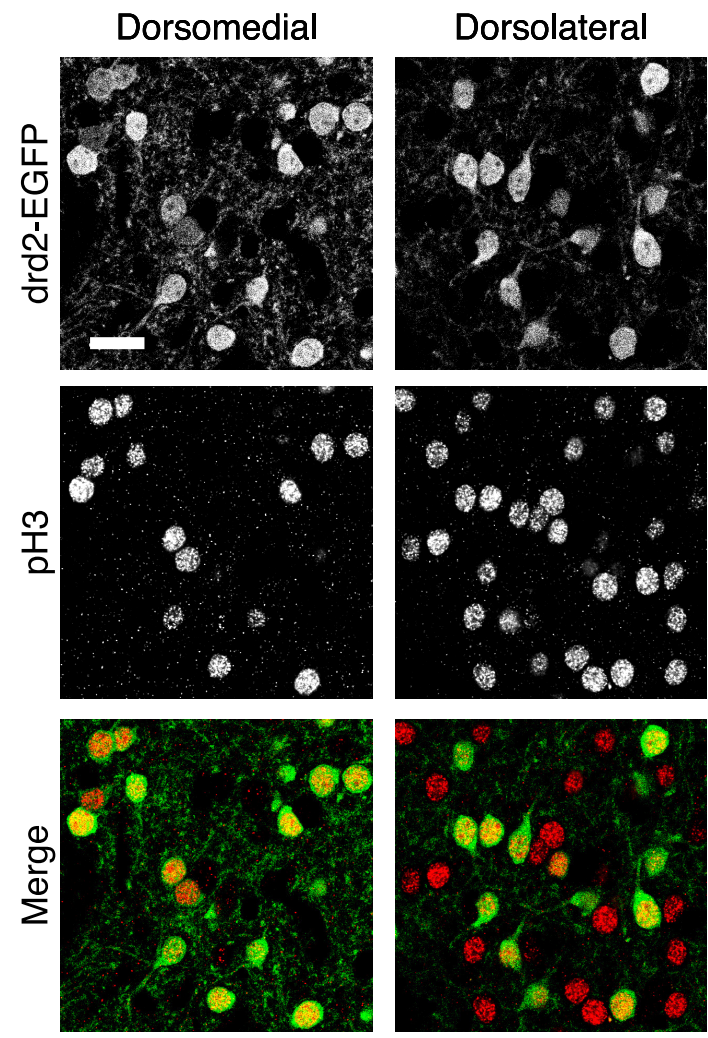

Brain slices

D

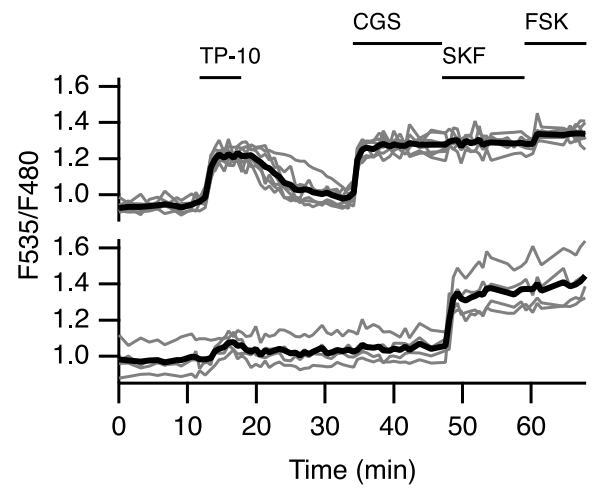

B

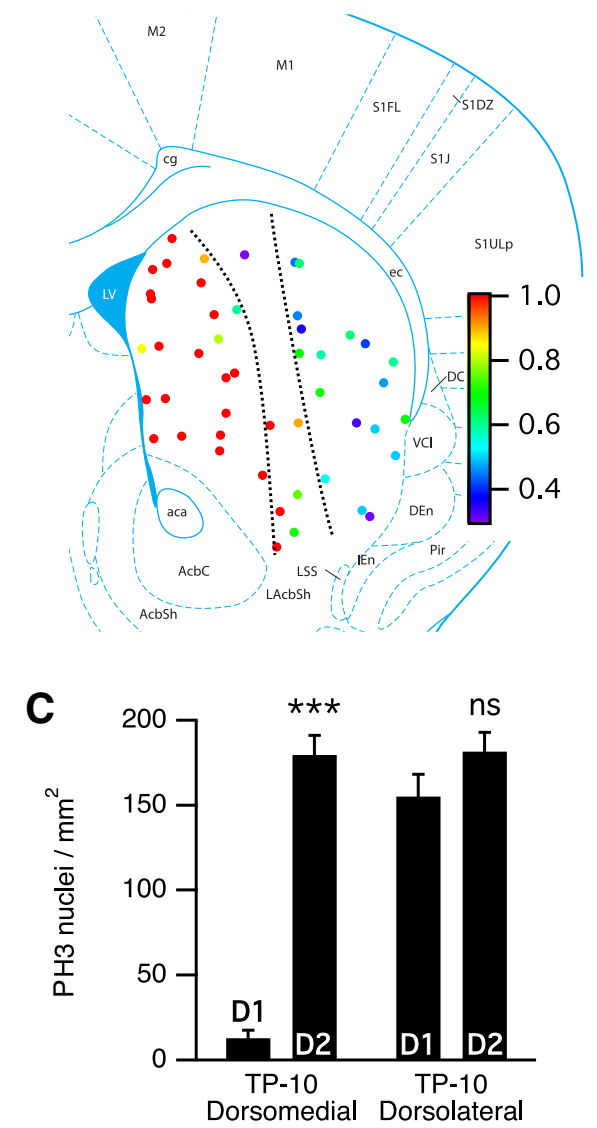

E

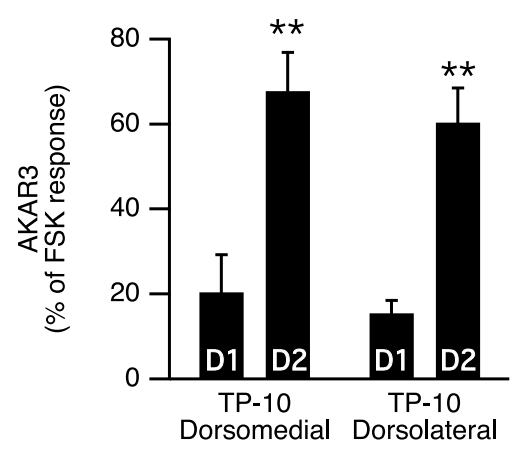

Figure 5. In vivo effects of PDE10A inhibition by TP-10. $\boldsymbol{A}$, In the medial part of the dorsal striatum of drd2-EGFP adult mice treated with TP-10 (3 mg/kg), PH3 was selectively observed in $\mathrm{D}_{2} \mathrm{MSNs}$. In the lateral part of the dorsal striatum, PH3 immunoreactivity was observed in both EGFP-positive and EGFP-negative MSNs. EGFP and PH3 are shown in grayscale, and are overlaid with EGFP in green and $\mathrm{PH} 3$ in red (Merge). Scale bar, $20 \mu \mathrm{m}$. B. Each color spot represents a position where the relative distribution of $\mathrm{D}_{2} /\left(\mathrm{D}_{1}+\right.$ $\mathrm{D}_{2}$ ) PH3-positive MSNs is indicated in pseudocolor, over a schematic of coronal mouse brain (Franklin and Paxinos, 2007). $\boldsymbol{C}$, PH3-positive nuclei were quantified in medial and lateral parts of the dorsal striatum as defined by the dotted line in $\boldsymbol{B}$. The effect of localization was significant (Kruskal-Wallis test followed by a Mann-Whitney test with a Dunn-Sidak adjustment test for pairwise multiple comparisons tests, $p<10^{-4}$ ), with $\mathrm{PH} 3$-positive nuclei being preferentially $\mathrm{D}_{2} \mathrm{MSN}$ in the medial striatum. $* * * i n d i c a t e s$ a difference between EGFP-positive $\left(D_{2}\right)$ and EGFP-negative $\left(D_{1}\right)$ MSNs with $p<10^{-4}$. $\boldsymbol{D}$, The preferential AKAR3 response is also observed in the lateral striatum in brain slices from neonate mice. MSNs were transduced for the expression of the AKAR3 biosensor and imaged with wide-field microscope in the lateral striatum. Each trace on the graph indicates the ratio measurement on MSNs expressing AKAR3 and was identified as $D_{1}$ or $D_{2}$ according to their response to either SKF-38393 (SKF, $\left.1 \mu \mathrm{M}\right)$ or CGS 21680 (CGS, 
continued

$1 \mu \mathrm{M})$, respectively. The thick black line represents the average of all the traces in each group. TP-10 (100 nm) increased AKAR3 ratio selectively in $D_{2}$ MSNs. $\boldsymbol{E}$, The same experiment was repeated: there was no effect of localization, and TP-10 increased the AKAR3 ratio selectively in $D_{2}$ MSNs in both the dorsolateral and dorsomedial striatum (two-way ANOVA: localization effect, $F_{(1,12)}=0.374$, $p=0.374 ; D_{1} / D_{2}$ effect, $F_{(1,12)}=44.01, p<10^{-4}$; localization $\times D_{1} / D_{2}$ interaction, $F_{(1,12)}=0.042, p=0.804$. Bonferroni's post hoc test: $* * p<0.01$.). $\boldsymbol{C}, \boldsymbol{E}$, Error bars indicate the SEM.

hypothesis implies that a powerful mechanism prevents DARPP-32 from remaining phosphorylated on the Thr34 position selectively in $D_{1}$ MSNs. Thr34 residue is efficiently dephosphorylated by both PP-2A and PP-2B (but not by PP-1; Nishi et al., 1999), and further work is needed to analyze the possible differences in PP2A and PP2B activities between $D_{1}$ and $D_{2} M S N s$. In contrast to tonic cAMP levels induced by PDE10A inhibition, cAMP signals elicited by $D_{1}$ receptor stimulation lead to a phosphorylation of T34 and inhibition of PP-1 (Bateup et al., 2008), an effect that is also clearly visible on transient responses to dopamine stimulations (Castro et al., 2013). This is consistent with the observation that, in $D_{1}$ MSNs, PDE10A inhibition only affects PKA-dependent modulation of synaptic transmission when CAMP production is stimulated (Mango et al., 2014). This nonlinearity in $D_{1}$ MSNs may improve the detection of powerful but brief events such as the phasic dopamine signal associated with reward and novelty (Schultz, 2010), while filtering out smaller fluctuations in basal cAMP level.

In contrast, in $\mathrm{D}_{2}$ MSNs DARPP-32 is phosphorylated on the Thr34 residue, as previously demonstrated (Nishi et al., 2008). In this situation, a moderate cAMP signal, such as that produced by PDE10A inhibition, activates PKA, and, because PP-1 is inhibited, PKA targets remain phosphorylated. Indeed, when DARPP-32 bears the T34A mutation and can no longer inhibit PP-1, $D_{2}$ MSNs fail to respond to PDE10A inhibition (Fig. 7).

Further work is needed to analyze the possible differences in PP-2A and PP-2B activities between $D_{1}$ and $D_{2}$ MSNs that may contribute to the higher level of DARPP-32 phosphorylation on Thr34

Another potential player in the $D_{1} / D_{2}$ differences is the phosphorylation of DARPP-32 on Thr75, which is catalyzed by Cdk5 and is responsible for PKA inhibition (Bibb et al., 1999). Since Thr75 is dephosphorylated by a PKAactivated form of PP-2A containing the B56 subunit (Ahn et al., 2007), it could contribute to a hypersensitive feedforward loop. However, this mechanism did not appear to be critical for PDE10A responses in $D_{2}$ MSNs, since we found no alteration of these responses in DARPP-32 T75A knock-in mutant mice.

The increased responsiveness of $D_{2} M S N s$ at the level of PKA signaling is opposed in vivo by the activity of $D_{2}$ receptors: the simple blockade of these receptors by $D_{2}$ antagonists strongly activates CAMP-dependent phos-
A
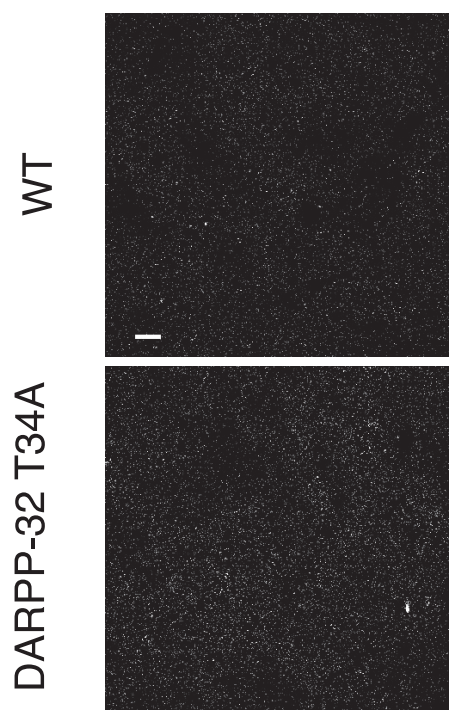

TP-10

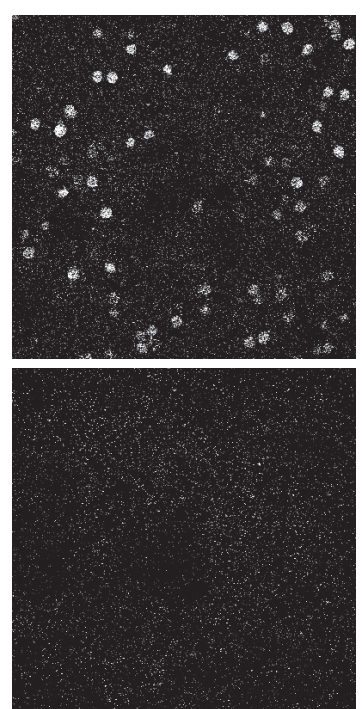

B

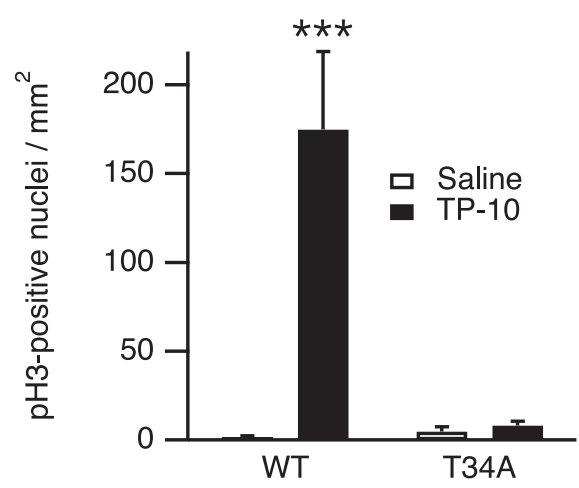

Figure 6. The DARPP-32 T34 residue is required for a TP-10-induced increase of histone H3 phosphorylation in the striatum in adult mice in vivo. Wild type (WT) and DARPP-32 T34A mutant mice were treated with TP-10 (3 mg/kg) or vehicle. A, Examples of PH3 immunofluorescence, showing the dramatic reduction of TP-10 effects in the DARPP-32 T34A mutant mice. Scale bar, $20 \mu \mathrm{m} . \boldsymbol{B}$, Quantification of the number of PH3-positive neurons in striatal coronal sections. Error bars indicate the SEM. Data were analyzed by a two-way ANOVA: genotype effect, $\mathrm{F}_{(1,12)}=13.7, p<0.01 ;$ TP-10 effect, $\mathrm{F}_{(1,12)}=16.1, p<0.01$; genotype $\times$ TP-10 interaction, $\mathrm{F}_{(1,12)}=14.8, p<0.01$. Bonferroni's post hoc test, $* * * p<10^{-3}$. 
D1 MSN

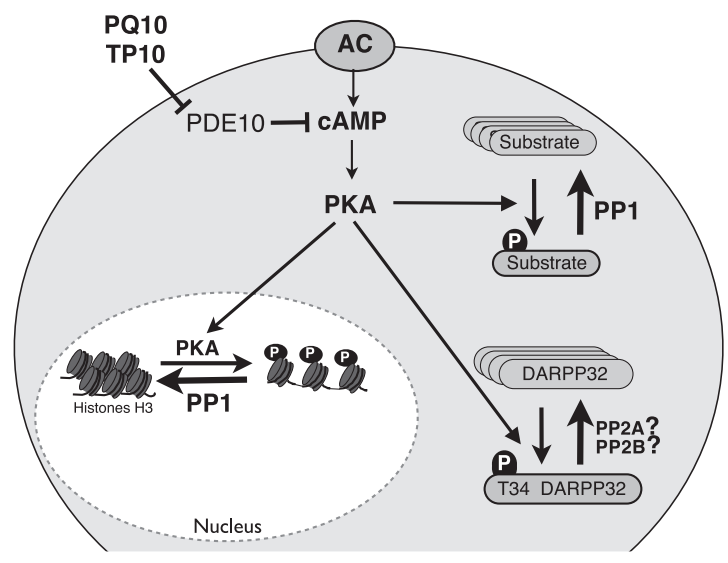

D2 MSNs

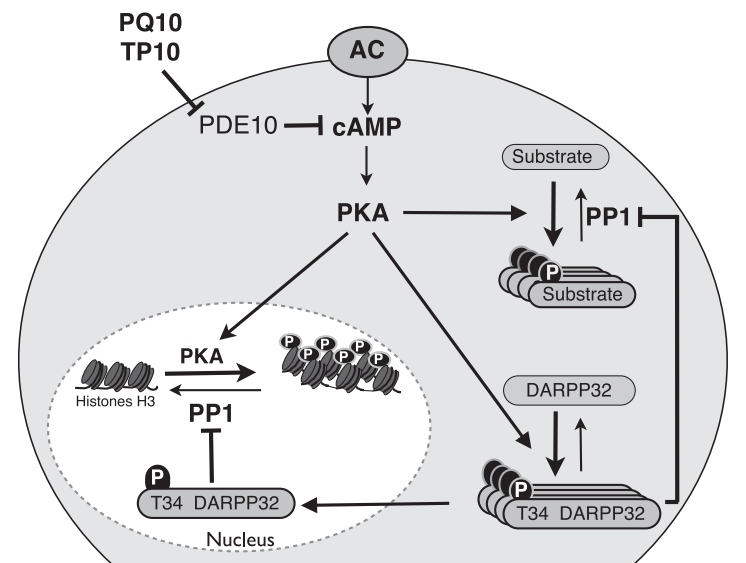

Figure 7. Diagram depicting the $D_{1} / D_{2}$ differential response to PDE10A inhibition. PDE10A inhibition increases cAMP and activates PKA to similar levels in $D_{1}$ and $D_{2}$ MSNs. In $D_{2}$ MSNs, DARPP-32 is phosphorylated and inhibits PP-1: PKA substrates thus remain in the phosphorylated state, both in the cytosol and in the nucleus. In $D_{1}$ MSNs, DARPP-32 is in a dephosphorylated state: PP-1 is fully active and dephosphorylates PKA substrates. Differences in PP2A/B activities between $D_{1}$ and $D_{2} M_{S N}$ may explain this imbalance.

phorylation (Håkansson et al., 2006; Bertran-Gonzalez et al., 2008, 2009; Bonito-Oliva et al., 2011; Valjent et al., 2011). Accordingly, haloperidol or clozapine selectively increases phospho-Thr34-DARPP-32 in $\mathrm{D}_{2} \mathrm{MSNs}$, and not in $D_{1}$ MSNs (Bateup et al., 2008). This role of DARPP-32 in $D_{2}$ MSNs is functionally important for some effects of antipsychotic drugs since conditional knockout of DARPP-32 in $\mathrm{D}_{2}$ MSNs leads to an increased locomotor activity and a strongly reduced catalepsy upon administration of $D_{2}$ receptor inhibitors (Bateup et al., 2010). Our data show that the inhibition of PDE10A has functional effects that are similar to the blockade of $D_{2}$ receptors since both potentiate the PKA pathway selectively in $D_{2}$ MSNs. The particular sensitivity of $D_{2}$ MSNs includes DARPP-32 Thr34 phosphorylation, which is more increased by PDE10A inhibitors in this population than in $D_{1}$ MSNs (Nishi et al., 2008). Thus, hypersensitivity of DARPP-32 Thr34 phosphorylation could be a critical factor to account for the responsiveness of $D_{2} M S N s$ to the blockade of either $D_{2}$ receptors or PDE10A activity.

The cellular effects of PDE10A inhibition affect MSNs neuronal properties, which are integrated through the basal ganglia network. For example, PDE10A inhibition was shown to potentiate D-amphetamine-dependent dopaminergic neuromodulation in vivo (Sotty et al., 2009). In addition, PDE10A inhibition was shown to massively increase cGMP levels in vivo (Siuciak et al., 2006; Schmidt et al., 2008; Grauer et al., 2009), whereas, no effect was observed in brain slice preparations (Nishi et al., 2008; this study). This discrepancy possibly results from the recruitment of striatal NOergic interneurons through network activity resulting indirectly from PDE10A inhibition.

In vivo, the inhibition of PDE10A also selectively activates $D_{2}$ MSNs in the medial striatum. Interestingly, this striatal subregion is innervated by prefrontal and cingulate cortices, which are involved in the limbic system, and dopamine neurons originating from the ventral tegmental area. $D_{1}$ and $D_{2}$ receptors exert contrasting roles selectively in the dorsomedial striatum during behavioral inhibition in the stop-signal task in rats (Eagle et al., 2011), and lesions of the dorsomedial striatum disrupt prepulse inhibition (Baldan Ramsey et al., 2011). This region is also involved in early motor learning and is required for the cataleptic effects of haloperidol and for amphetamine motor response sensitization (Durieux et al., 2012). Medial striatum thus appears as a limbic system-related region that could be affected in schizophrenia.

The differences observed between medial and lateral striatum likely involve network effects and differences in synaptic plasticity reported between these two striatal subregions (Lovinger, 2010), and further work should precisely show how these spatial differences are related to behavior. Our work nonetheless shows that the $D_{1} / D_{2}$ difference is present in brain slices in both medial and lateral striatum, and remains when network activity is blocked, showing that the $D_{1} / D_{2}$ difference is an intrinsic property of $D_{1}$ and $D_{2}$ MSNs. The in vivo effects of PDE10A inhibitors were totally abolished in T34DARPP-32 mutant mice, confirming the role of the DARPP-32/PP-1 loop as the initial determinant of the positive PKA response obtained during PDE10A inhibition.

Further work is needed to determine whether the imbalance in PKA signal integration between $D_{1}$ and $D_{2}$ MSNs might be of interest to understand the pathophysiology of other diseases that affect neuromodulatory processes in basal ganglia such as Parkinson's disease or Huntington's disease (Threlfell and West, 2013). 


\section{References}

Ahn JH, Sung JY, McAvoy T, Nishi A, Janssens V, Goris J, Greengard P, Nairn AC (2007) The B'"/PR72 subunit mediates Ca2+dependent dephosphorylation of DARPP-32 by protein phosphatase 2A. Proc Natl Acad Sci U S A 104:9876-9881. CrossRef Medline[Mismatch]

Allen MD, Zhang J (2006) Subcellular dynamics of protein kinase A activity visualized by FRET-based reporters. Biochem Biophys Res Commun 348:716-721. CrossRef Medline

Baldan Ramsey LC, Xu M, Wood N, Pittenger C (2011) Lesions of the dorsomedial striatum disrupt prepulse inhibition. Neuroscience 180:222-228. CrossRef Medline

Bateup HS, Santini E, Shen W, Birnbaum S, Valjent E, Surmeier DJ, Fisone G, Nestler EJ, Greengard P (2010) Distinct subclasses of medium spiny neurons differentially regulate striatal motor behaviors. Proc Natl Acad Sci U S A 107:14845-14850. CrossRef Medline

Bateup HS, Svenningsson P, Kuroiwa M, Gong S, Nishi A, Heintz N, Greengard P (2008) Cell type-specific regulation of DARPP-32 phosphorylation by psychostimulant and antipsychotic drugs. Nat Neurosci 11:932-939. CrossRef Medline

Bertran-Gonzalez J, Bosch C, Maroteaux M, Matamales M, Hervé D, Valjent E, Girault JA (2008) Opposing patterns of signaling activation in dopamine $D_{1}$ and $D_{2}$ receptor-expressing striatal neurons in response to cocaine and haloperidol. J Neurosci 28:5671-5685. CrossRef Medline

Bertran-Gonzalez J, Håkansson K, Borgkvist A, Irinopoulou T, BramiCherrier K, Usiello A, Greengard P, Hervé D, Girault JA, Valjent E, Fisone $\mathrm{G}$ (2009) Histone H3 phosphorylation is under the opposite tonic control of dopamine D2 and adenosine A2A receptors in striatopallidal neurons. Neuropsychopharmacology 34:17101720. CrossRef Medline

Bibb JA, Snyder GL, Nishi A, Yan Z, Meijer L, Fienberg AA, Tsai LH, Kwon YT, Girault JA, Czernik AJ, Huganir RL, Hemmings HCJ, Nairn AC, Greengard P (1999) Phosphorylation of DARPP-32 by Cdk5 modulates dopamine signalling in neurons. Nature 402:669671. CrossRef Medline

Bonito-Oliva A, Feyder M, Fisone G (2011) Deciphering the Actions of Antiparkinsonian and Antipsychotic Drugs on cAMP/DARPP-32 Signaling. Front Neuroanat 5:38. CrossRef Medline

Castro LR, Brito M, Guiot E, Polito M, Korn CW, Hervé D, Girault JA, Paupardin-Tritsch D, Vincent P (2013) Striatal neurones have a specific ability to respond to phasic dopamine release. J Physiol 591:3197-3214. CrossRef Medline

Castro LR, Gervasi N, Guiot E, Cavellini L, Nikolaev VO, PaupardinTritsch D, Vincent P (2010) Type 4 phosphodiesterase plays different integrating roles in different cellular domains in pyramidal cortical neurons. J Neurosci 30:6143-6151. CrossRef Medline

Chappie TA, Helal CJ, Hou X (2012) Current landscape of phosphodiesterase 10A (PDE10A) inhibition. J Med Chem 55:7299-7331. CrossRef Medline

Charych El, Jiang LX, Lo F, Sullivan K, Brandon NJ (2010) Interplay of palmitoylation and phosphorylation in the trafficking and localization of phosphodiesterase 10A: implications for the treatment of schizophrenia. J Neurosci 30:9027-9037. CrossRef Medline

Coskran TM, Morton D, Menniti FS, Adamowicz WO, Kleiman RJ, Ryan AM, Strick CA, Schmidt CJ, Stephenson DT (2006) Immunohistochemical localization of phosphodiesterase 10A in multiple mammalian species. J Histochem Cytochem 54:1205-1213. CrossRef Medline

Ducros M, Moreaux L, Bradley J, Tiret P, Griesbeck O, Charpak S (2009) Spectral unmixing: analysis of performance in the olfactory bulb in vivo. PLoS One 4:e4418. CrossRef Medline

Durieux PF, Schiffmann SN, de Kerchove d'Exaerde A (2012) Differential regulation of motor control and response to dopaminergic drugs by D1R and D2R neurons in distinct dorsal striatum subregions. EMBO J 31:640-653. CrossRef Medline

Eagle DM, Wong JC, Allan ME, Mar AC, Theobald DE, Robbins TW (2011) Contrasting roles for dopamine $D_{1}$ and $D_{2}$ receptor sub- types in the dorsomedial striatum but not the nucleus accumbens core during behavioral inhibition in the stop-signal task in rats. $J$ Neurosci 31:7349-7356. CrossRef Medline

Ehrengruber MU, Lundstrom K, Schweitzer C, Heuss C, Schlesinger S, Gahwiler BH (1999) Recombinant Semliki Forest virus and Sindbis virus efficiently infect neurons in hippocampal slice cultures. Proc. Natl. Acad. Sci. U S A 96:7041-7046. Medline [Mismatch]

Ferré S, Fredholm BB, Morelli M, Popoli P, Fuxe K (1997) Adenosinedopamine receptor-receptor interactions as an integrative mechanism in the basal ganglia. Trends Neurosci 20:482-487. Medline

Franklin KBJ, Paxinos G (2007) The mouse brain in stereotaxic coordinates, Ed 3. New York: Elsevier.

Gerfen CR, Engber TM, Mahan LC, Susel Z, Chase TN, Monsma FJJ, Sibley DR (1990) D1 and D2 dopamine receptor-regulated gene expression of striatonigral and striatopallidal neurons. Science 250:1429-1432. Medline

Gertler TS, Chan CS, Surmeier DJ (2008) Dichotomous anatomical properties of adult striatal medium spiny neurons. J Neurosci 28:10814-10824. CrossRef Medline

Gervasi N, Hepp R, Tricoire L, Zhang J, Lambolez B, PaupardinTritsch D, Vincent $P$ (2007) Dynamics of protein kinase A signaling at the membrane, in the cytosol, and in the nucleus of neurons in mouse brain slices. J Neurosci 27:2744-2750. CrossRef Medline Girault JA (2012) Integrating neurotransmission in striatal medium spiny neurons. Adv Exp Med Biol 970:407-429. CrossRef Medline

Gong S, Zheng C, Doughty ML, Losos K, Didkovsky N, Schambra UB, Nowak NJ, Joyner A, Leblanc G, Hatten ME, Heintz N (2003) A gene expression atlas of the central nervous system based on bacterial artificial chromosomes. Nature 425:917-925. CrossRef Medline

Grauer SM, Pulito VL, Navarra RL, Kelly M, Kelley C, Graf R, Langen B, Logue S, Brennan J, Jiang L, Charych E, Egerland U, Liu F, Marquis KL, Malamas M, Hage T, Comery TA, Brandon NJ (2009) Phosphodiesterase 10A inhibitor activity in preclinical models of the positive, cognitive and negative symptoms of schizophrenia. $\mathrm{J}$ Pharmacol Exp Ther 331:574-590. CrossRef Medline

Håkansson K, Galdi S, Hendrick J, Snyder G, Greengard P, Fisone G (2006) Regulation of phosphorylation of the GluR1 AMPA receptor by dopamine D2 receptors. J Neurochem 96:482-488. CrossRef Medline

Heiman M, Schaefer A, Gong S, Peterson JD, Day M, Ramsey KE, Suárez-Fariñas M, Schwarz C, Stephan DA, Surmeier DJ, Greengard P, Heintz N (2008) A translational profiling approach for the molecular characterization of CNS cell types. Cell 135:738-748. CrossRef Medline

Hemmings HC Jr, Greengard P, Tung HY, Cohen P (1984) DARPP32 , a dopamine-regulated neuronal phosphoprotein, is a potent inhibitor of protein phosphatase-1. Nature 310:503-505. Medline

Honda A, Adams SR, Sawyer CL, Lev-Ram V, Tsien RY, Dostmann WRG (2001) Spatiotemporal dynamics of guanosine 3',5'-cyclic monophosphate revealed by a genetically encoded, fluorescent indicator. Proc Natl Acad Sci U S A 98:2437-2442. CrossRef Medline

Janssen MJ, Ade KK, Fu Z, Vicini S (2009) Dopamine modulation of GABA tonic conductance in striatal output neurons. J Neurosci 29:5116-5126. CrossRef Medline

Jordi E, Heiman M, Marion-Poll L, Guermonprez P, Cheng SK, Nairn AC, Greengard P, Girault JA (2013) Differential effects of cocaine on histone posttranslational modifications in identified populations of striatal neurons. Proc Natl Acad Sci U S A 110:9511-9516. CrossRef Medline

Kehler J, Nielsen J (2011) PDE10A inhibitors: novel therapeutic drugs for schizophrenia. Curr Pharm Des 17:137-150. Medline

Kelly MP, Adamowicz W, Bove S, Hartman AJ, Mariga A, Pathak G, Reinhart V, Romegialli A, Kleiman RJ (2014) Select 3',5'-cyclic nucleotide phosphodiesterases exhibit altered expression in the aged rodent brain. Cell Signal 26:383-397. CrossRef Medline

Kotera J, Sasaki T, Kobayashi T, Fujishige K, Yamashita Y, Omori K (2004) Subcellular localization of cyclic nucleotide phosphodies- 
terase type $10 \mathrm{~A}$ variants, and alteration of the localization by cAMP-dependent protein kinase-dependent phosphorylation. $\mathrm{J}$ Biol Chem 279:4366-4375. CrossRef Medline

Lakics V, Karran EH, Boess FG (2010) Quantitative comparison of phosphodiesterase mRNA distribution in human brain and peripheral tissues. Neuropharmacology 59:367-374. CrossRef Medline

Le Moine C, Bloch B (1995) D1 and D2 dopamine receptor gene expression in the rat striatum: sensitive cRNA probes demonstrate prominent segregation of D1 and D2 mRNAs in distinct neuronal populations of the dorsal and ventral striatum. J Comp Neurol 355:418-426. CrossRef Medline

Lovinger DM (2010) Neurotransmitter roles in synaptic modulation, plasticity and learning in the dorsal striatum. Neuropharmacology 58:951-961. CrossRef Medline

Mango D, Bonito-Oliva A, Ledonne A, Nistico R, Castelli V, Giorgi M, Sancesario G, Fisone G, Berretta N, Mercuri NB (2014) Phosphodiesterase $10 \mathrm{~A}$ controls D1-mediated facilitation of GABA release from striato-nigral projections under normal and dopaminedepleted conditions. Neuropharmacology 76:127-136. CrossRef Medline

Matamales M, Bertran-Gonzalez J, Salomon L, Degos B, Deniau JM, Valjent E, Hervé D, Girault JA (2009) Striatal medium-sized spiny neurons: identification by nuclear staining and study of neuronal subpopulations in BAC transgenic mice. PLoS One 4:e4770. CrossRef Medline

Nguyen QT, Tsai PS, Kleinfeld D (2006) MPScope: a versatile software suite for multiphoton microscopy. J Neurosci Methods 156: 351-359. CrossRef Medline

Nishi A, Bibb JA, Snyder GL, Higashi H, Nairn AC, Greengard P (2000) Amplification of dopaminergic signaling by a positive feedback loop. Proc Natl Acad Sci U S A 97:12840-12845. CrossRef Medline

Nishi A, Kuroiwa M, Miller DB, O'Callaghan JP, Bateup HS, Shuto T, Sotogaku N, Fukuda T, Heintz N, Greengard P, Snyder GL (2008) Distinct roles of PDE4 and PDE10A in the regulation of CAMP/PKA signaling in the striatum. J Neurosci 28:10460-10471. CrossRef Medline

Nishi A, Snyder GL, Nairn AC, Greengard P (1999) Role of calcineurin and protein phosphatase-2A in the regulation of DARPP-32 dephosphorylation in neostriatal neurons. J Neurochem 72:20152021. Medline

Nowak SJ, Corces VG (2004) Phosphorylation of histone H3: a balancing act between chromosome condensation and transcriptional activation. Trends Genet 20:214-220. CrossRef Medline

Padovan-Neto FE, Sammut S, Chakroborty S, Dec AM, Threlfell S, Campbell PW, Mudrakola V, Harms JF, Schmidt CJ, West AR (2015) Facilitation of corticostriatal transmission following pharmacological inhibition of striatal phosphodiesterase $10 \mathrm{~A}$ : role of nitric oxide-soluble guanylyl cyclase-cGMP signaling pathways. J Neurosci 35:5781-5791. CrossRef Medline

Polito M, Klarenbeek J, Jalink K, Paupardin-Tritsch D, Vincent P, Castro LR (2013) The NO/cGMP pathway inhibits transient cAMP signals through the activation of PDE2 in striatal neurons. Front Cell Neurosci 7:211. CrossRef Medline

Russwurm C, Koesling D, Russwurm M (2015) Phosphodiesterase $10 \mathrm{~A}$ is tethered to a synaptic signaling complex in striatum. J Biol Chem 290:11936-11947. CrossRef Medline

Schiffmann SN, Jacobs O, Vanderhaeghen JJ (1991) Striatal restricted adenosine $\mathrm{A} 2$ receptor (RDC8) is expressed by enkephalin but not by substance $P$ neurons: an in situ hybridization histochemistry study. J Neurochem 57:1062-1067. Medline

Schiffmann SN, Vanderhaeghen JJ (1993) Adenosine A2 receptors regulate the gene expression of striatopallidal and striatonigral neurons. J Neurosci 13:1080-1087. Medline

Schmidt CJ, Chapin DS, Cianfrogna J, Corman ML, Hajos M, Harms JF, Hoffman WE, Lebel LA, McCarthy SA, Nelson FR, ProulxLaFrance C, Majchrzak MJ, Ramirez AD, Schmidt K, Seymour PA,
Siuciak JA, Tingley FD, Williams RD, Verhoest PR, Menniti FS (2008) Preclinical characterization of selective phosphodiesterase 10A inhibitors: a new therapeutic approach to the treatment of schizophrenia. J Pharmacol Exp Ther 325:681-690. CrossRef Medline

Schultz W (2010) Dopamine signals for reward value and risk: basic and recent data. Behav Brain Funct 6:24. CrossRef Medline

Seeger TF, Bartlett B, Coskran TM, Culp JS, James LC, Krull DL, Lanfear J, Ryan AM, Schmidt CJ, Strick CA, Varghese AH, Williams RD, Wylie PG, Menniti FS (2003) Immunohistochemical localization of PDE10A in the rat brain. Brain Res. 985:113-126. Medline

Siuciak JA, Chapin DS, Harms JF, Lebel LA, McCarthy SA, Chambers L, Shrikhande A, Wong S, Menniti FS, Schmidt CJ (2006) Inhibition of the striatum-enriched phosphodiesterase PDE10A: a novel approach to the treatment of psychosis. Neuropharmacology 51:386-396. CrossRef Medline

Sotty F, Montezinho LP, Steiniger-Brach B, Nielsen J (2009) Phosphodiesterase $10 \mathrm{~A}$ inhibition modulates the sensitivity of the mesolimbic dopaminergic system to D-amphetamine: involvement of the D1-regulated feedback control of midbrain dopamine neurons. J Neurochem 109:766-775. CrossRef Medline

Svenningsson P, Le Moine C, Fisone G, Fredholm BB (1999) Distribution, biochemistry and function of striatal adenosine A2A receptors. Prog Neurobiol 59:355-396. Medline

Svenningsson P, Nishi A, Fisone G, Girault JA, Nairn AC, Greengard P (2004) DARPP-32: an integrator of neurotransmission. Annu Rev Pharmacol Toxicol 44:269-296. CrossRef Medline

Svenningsson P, Tzavara ET, Carruthers R, Rachleff I, Wattler S, Nehls M, McKinzie DL, Fienberg AA, Nomikos GG, Greengard P (2003) Diverse psychotomimetics act through a common signaling pathway. Science 302:1412-1415. CrossRef Medline

Swingle MR, Amable L, Lawhorn BG, Buck SB, Burke CP, Ratti P, Fischer KL, Boger DL, Honkanen RE (2009) Structure-activity relationship studies of fostriecin, cytostatin, and key analogs, with PP1, PP2A, PP5, and(beta12-beta13)-chimeras (PP1/PP2A and PP5/PP2A), provide further insight into the inhibitory actions of fostriecin family inhibitors. J Pharmacol Exp Ther 331:45-53. CrossRef Medline

Threlfell S, Sammut S, Menniti FS, Schmidt CJ, West AR (2009) Inhibition of phosphodiesterase 10A increases the responsiveness of striatal projection neurons to cortical stimulation. J Pharmacol Exp Ther 328:785-795. CrossRef Medline

Threlfell S, West AR (2013) Review: modulation of striatal neuron activity by cyclic nucleotide signaling and phosphodiesterase inhibition. Basal Ganglia 3:137-146. CrossRef Medline

Valjent E, Bertran-Gonzalez J, Bowling H, Lopez S, Santini E, Matamales M, Bonito-Oliva A, Hervé D, Hoeffer C, Klann E, Girault JA, Fisone $G$ (2011) Haloperidol regulates the state of phosphorylation of ribosomal protein S6 via activation of PKA and phosphorylation of DARPP-32. Neuropsychopharmacology 36:2561-2570. CrossRef Medline

Valjent E, Bertran-Gonzalez J, Hervé D, Fisone G, Girault JA (2009) Looking BAC at striatal signaling: cell-specific analysis in new transgenic mice. Trends Neurosci 32:538-547. CrossRef Medline Yagishita S, Hayashi-Takagi A, Ellis-Davies GC, Urakubo H, Ishii S, Kasai $H$ (2014) A critical time window for dopamine actions on the structural plasticity of dendritic spines. Science 345:1616-1620. CrossRef Medline

Yang L, Gilbert ML, Zheng R, McKnight GS (2014) Selective expression of a dominant-negative type $1 \alpha$ PKA regulatory subunit in striatal medium spiny neurons impairs gene expression and leads to reduced feeding and locomotor activity. J Neurosci 34:48964904. CrossRef Medline

Zhang J, Hupfeld CJ, Taylor SS, Olefsky JM, Tsien RY (2005) Insulin disrupts beta-adrenergic signalling to protein kinase $A$ in adipocytes. Nature 437:569-573. CrossRef Medline 